\title{
1 Cryptic diversity within the Poecilochirus carabi mite 2 species complex phoretic on Nicrophorus burying 3 beetles: phylogeny, biogeography, and host specificity
}

4 Julia Canitz ${ }^{1}$, Derek S. Sikes ${ }^{2}$, Wayne Knee ${ }^{3}$, Julia Baumann ${ }^{4}$, Petra Haftaro ${ }^{1}$,

5 Nadine Steinmetz ${ }^{1}$, Martin Nave ${ }^{1}$, Anne-Katrin Eggert ${ }^{5}$, Wenbe Hwang ${ }^{6}$, Volker

6 Nehring ${ }^{1}$

$7 \quad{ }^{1}$ Institute for Biology I, University of Freiburg, Hauptstraße 1, Freiburg, Germany

$8{ }^{2}$ University of Alaska Museum, University of Alaska Fairbanks, Fairbanks, Alaska, 999775 , USA

$10{ }^{3}$ Canadian National Collection of Insects, Arachnids, and Nematodes, Agriculture and 11 Agri-Food Canada, 960 Carling Avenue, K.W. Neatby Building, Ottawa, Ontario, 12 K1A 0C6, Canada

$13{ }^{4}$ Institute of Biology, University of Graz, Universitätsplatz 2, 8010 Graz, Austria

$14{ }^{5}$ School of Biological Sciences, Illinois State University, Normal, IL 61790-4120, USA

$15{ }^{6}$ Department of Ecology and Environmental Resources, National Univ. of Tainan, 33

16 Shulin St., Sec. 2, West Central Dist, Tainan 70005, Taiwan

17 Correspondence: volker.nehring@biologie.uni-freiburg.de 


\section{Abstract}

19 Coevolution is often considered a major driver of speciation, but evidence for this claim

20 is not always found because diversity might be cryptic. When morphological divergence

21 is low, molecular data are needed to uncover diversity. A taxon for which this holds true

22 are the mites, which are known for their extensive and often cryptic diversity. We

23 studied mites of the genus Poecilochirus that are phoretic on burying beetles (Silphidae:

24 Nicrophorus). Poecilochirus taxonomy is poorly understood. Most studies on this genus

25 focus on the evolutionary ecology of Poecilochirus carabi sensu lato, a complex of at

26 least two biological species. Based on molecular data of 230 specimens from

2743 locations worldwide, we identified 24 genetic clusters that may represent species.

28 We estimate that these mites began to diversify during the Paleogene, when the clade

29 containing $P$. subterraneus branched off and the remaining mites diverged into two

30 further clades. One clade resembles $P$. monospinosus and $P$. austroasiaticus. The other

31 clade contains 17 genetic clusters resembling $P$. carabi s.l.. Among these are $P$. carabi

32 sensu stricto, $P$. necrophori, and potentially many additional cryptic species. Our

33 analyses suggest that these clades were formed in the miocene by large-scale geographic

34 separation. Diversification also seems to have happened on a smaller scale, potentially

35 due to adaptation to specific hosts or local abiotic conditions, causing some clusters to

36 specialize on certain beetle species. Our results suggest that biodiversity in this genus

37 was generated by multiple interacting forces shaping the tangled webs of life. 


\section{Introduction}

39 Parasites are known for their high biodiversity (García-Varela et al., 2011; Huyse et al.,

40 2005; Magalhães et al., 2007). In all organisms, geographic separation can lead to

41 allopatric speciation, and ecological factors may cause disruptive selection and lead to

42 reproductive isolation in sympatry (Butlin et al., 2012). Ecological effects are amplified

43 by the interaction of parasites with their hosts: Any divergence in host populations can

44 potentially alter selection on the parasites and lead to divergence and even co-speciation

45 with their hosts (Hoberg et al., 1997). Further, reciprocal selection between hosts and

46 parasites may speed up evolution and lead to higher diversification rates among

47 populations (Paterson et al., 2010; Thompson, 2009; Yoder \& Nuismer, 2010). These

48 processes can result in many parasite populations or species each specialized on just one

49 host species or population (García-Varela et al., 2011; Hunter \& Rosario, 1988; Huyse

50 et al., 2005; Magalhães et al., 2007; Perotti \& Braig, 2009). The diversity of parasites is

51 often cryptic, as they tend to live hidden lives and morphological adaptations to

52 parasitism may be similar for all hosts (García-Varela et al., 2011). Hence, the diversity

53 of parasites is likely underestimated.

54 The mite genus Poecilochirus G. \& R. Canestrini, 1882 (Mesostigmata: Parasitidae)

55 consists of 20 morphologically described species (Hyatt, 1980; Perotti \& Braig, 2009;

56 Ramaraju \& Madanlar, 1998). Several species are phoretic as immatures

57 (deutonymphs). They attach to adult burying beetles (Silphidae: Nicrophorus) for

58 dispersal (Farish \& Axtell, 1971; Schwarz \& Koulianos, 1998). The beetles bury small

59 vertebrate carcasses, on which they raise their offspring. While the parental beetles

60 provide brood care, Poecilochirus mites dismount from their host beetles, feed on

61 microorganisms, fly eggs, and sometimes beetle eggs, develop into adults, and

62 reproduce (Brown \& Wilson, 1992; Meierhofer et al., 1999; Schwarz \& Müller 1992). 
63 Deutonymphal mites disperse from the carcass by attaching to the parental beetles or

64 their adult offspring (Schwarz \& Koulianos, 1998; Schwarz \& Müller, 1992). At larger

65 carcasses, multiple beetle species can co-occur and mites can switch between host

66 individuals. Mites recognize their main host by olfactory cues and some prefer specific

67 Nicrophorus species over others (Korn, 1982; Müller \& Schwarz, 1990). If the preferred

68 host species is not available, the mites will mount other host species, but their fitness

69 may be reduced when they reproduce along with the 'wrong' host species (Brown \&

70 Wilson, 1994; Nehring et al., 2017). Such host switches may counteract host

71 specialization (Thompson, 2009).

72 There is no evidence that the mites affect host beetle fitness during the phoretic

73 dispersal. However, some observations suggest that mites may affect beetle fitness

74 during the reproduction phase. Depending on the environmental conditions, the mites

75 can either directly reduce beetle brood weight and offspring number (De Gasperin \&

76 Kilner, 2015; Nehring et al., 2019; Schedwill et al., 2020), or have positive effects on

77 beetle fitness by helping to fend off other competitors such as blowflies, nematodes, or

78 other beetles (Springett, 1968; Sun et al., 2019; Wilson \& Knollenberg, 1987). In any

79 case, whether the mites are parasites or mutualists, they have likely coevolved with the

80 host beetles.

81 Poecilochirus species can be distinguished morphologically based on body size, the

82 presence or absence of setae, the form and pattern of setae and the sternal shield, the

83 morphology of the chelicerae, and genital structures (Baker \& Schwarz, 1997; Hyatt,

84 1980; Ramaraju \& Madanlar, 1998; Wise et al., 1988). However, the taxonomy of the

85 genus is poorly understood, at least partly because morphological differences between

86 species are small (Mašán, 1999). The best-studied species is Poecilochirus carabi, but it

87 has been shown that this species actually consists of at least two reproductively isolated 
88 populations that occur sympatrically in Central Europe and that have been named $P$.

89 carabi sensu stricto and P. necrophori (Baker \& Schwarz, 1997; Hyatt, 1980; Müller \&

90 Schwarz, 1990). Field and laboratory studies indicate that $P$. necrophori is a host

91 specialist primarily found on Nicrophorus vespillo, while P. carabi s.s. is prevalent on

92 at least three different Nicrophorus species ( $N$. vespilloides, $N$. investigator, and $N$.

93 humator), but rarely on $N$. vespillo (Schwarz, 1996). Furthermore, two reproductively

94 isolated populations of $P$. carabi are specialized on two sympatric North American

95 Nicrophorus species ( $N$. tomentosus and $N$. orbicollis) and differ in morphology

96 (Brown, 1989; Brown \& Wilson, 1992), but their relationship to the European species is

97 unknown. Mites of these morphologically very similar but reproductively isolated and

98 ecologically well-defined populations are considered to belong to a cryptic species

99 complex, termed P. carabi sensu lato (Baker \& Schwarz, 1990; Masan, 1999).

100 One might expect that $P$. carabi s.l. consists of more than these four cryptic species, 101 given that the holarctic genus Nicrophorus includes more than 60 species (Sikes et al., 102 2002, 2016). Burying beetles originated in the Cretaceous (99-127 Ma) in Asia/Eurasia,

103 colonized the Western hemisphere and have likely back-migrated to Eurasia more than 104 once (Hatch, 1927; Peck \& Anderson, 1985; Sikes \& Venables, 2013). Today, most 105 species are restricted to single continents, and at most locations, multiple species occur 106 in sympatry (e.g. Brown \& Wilson, 1992; Dekeirsschieter et al., 2011). Only $N$. 107 vespilloides and $N$. investigator occur in both the Western and Eastern hemispheres 108 (Sikes et al., 2008; Sikes et al., 2016). Nicrophorus species vary in their habitat 109 preferences. Some species inhabit woodlands and others open areas, and differences in 110 the diel activity and reproductive season have been reported for species on both 111 continents (Anderson 1982, Burke et al., 2020; Esh \& Oxbrough, 2021; Majka, 2011; 112 Scott, 1998). 
113 Molecular, phylogenetic, and divergence time analyses have been conducted for

114 Nicrophorus (Sikes et al., 2008, 2016; Sikes \& Venables, 2013), but are missing for

115 Poecilochirus species. The scant genetic data that are available are primarily from

116 broader studies on the diversity and phylogenetics of Mesostigmata or Acari, with many

117 samples only identified to the genus level (Klompen et al., 2007; Rueda-Ramírez et al.,

118 2019; Young et al., 2019). The lack of molecular data on the diversity of this genus

119 prevents further insight into its ecology and evolutionary history.

120 In this study, we want to understand the evolutionary history of Poecilochirus mites that

121 are phoretic on Nicrophorus beetles, and P. carabi s.l. in particular, using molecular

122 analyses. Given the biodiversity and wide distribution of the host genus, and the

123 independent descriptions of reproductively isolated mite populations in Europe and

124 North America, we predicted that genetic diversity within the genus Poecilochirus is

125 currently underestimated. Based on the results of previous studies (Brown \& Wilson,

126 1992; Müller \& Schwarz, 1990), host specificity is expected to be evident in mite

127 genetics, as much of the mites' reproductive isolation is suggested to be caused by

128 diverging host preferences. We sequenced three genetic markers of Poecilochirus mites

129 collected with their Nicrophorus hosts on four different continents. We documented

130 their genetic diversity, reconstructed the phylogenetic relationships, and estimated

131 evolutionary divergence times to better understand the drivers of speciation in this mite

132 clade. 


\section{Materials and Methods}

134 We collected Poecilochirus mites from burying beetles from North and South America,

135 Europe and Asia and used nuclear and mitochondrial DNA sequences to identify genetic

136 clusters. We then reconstructed phylogenetic relationships, and analyzed the

137 biogeography and host specificity of the main mite clusters.

\section{Sampling}

139 We focused on mites from burying beetles that morphologically resemble $P$. carabi in

140 their habitus and body size (body length ca. $1 \mathrm{~mm}$; 218 individuals). Samples originated

141 from 43 different locations ranging from Alaska (USA), through Europe, Central Asia,

142 Japan and Melanesia (Figure S1). They were collected together with their host beetles,

143 including 31 Nicrophorus species and one carabid beetle (Pterostichus melanarius).

144 Specimens were sampled from the wild between 1998 and 2020, and were preserved

145 either in 96\% ethanol, propylene glycol, or kept dry (Supplement Table S1). Several

146 specimens of the German populations (Mooswald, Freiburg) could be identified as $P$.

147 necrophori or $P$. carabi s.s. by host preference tests following the description of

148 Nehring et al. (2017).

149 In addition, specimens identified as $P$. subterraneus $(\mathrm{n}=12)$ and Macrocheles sp. $(\mathrm{n}=$

150 2) were added to the data set to serve as the outgroup in phylogenetic analyses

151 (Supplement Table S1). Mite vouchers are deposited in the Sikes Research Collection at

152 the University of Alaska Fairbanks, the Canadian National Collection of Insects,

153 Arachnids, and Nematodes, and the Acarological Collection at the University of Graz. 


\section{Molecular Methods}

155 We extracted DNA from 232 mites. Two different methods were used for DNA

156 extraction. We applied either the Chloroform/Isopropanol method where the whole

157 individual was ground up in liquid nitrogen, or a non-destructive approach using the

158 DNeasy Blood and Tissue Kit (Qiagen). For the non-destructive method, we incubated

159 the entire specimen in 50 $\mu$ l lysis buffer (ATL buffer) and $10 \mu$ l Proteinase $\mathrm{K}$ for

160 approximately $24 \mathrm{~h}$ at $56^{\circ} \mathrm{C}$. After $6-8 \mathrm{~h}$, additional $5 \mu$ l Proteinase $\mathrm{K}$ were added.

161 Subsequently, we removed the undamaged specimens and followed the default protocol

162 of the DNeasy Kit. Mite voucher specimens following DNA extraction were preserved

163 in absolute ethanol.

164 A partial sequence of the Cytochrome Oxidase I gene (COI) was amplified using the 165 universal primer pair LCO1490 and HCO2198 (Folmer et al., 1994). Furthermore, the

166 ribosomal Internal Transcribed Spacer gene (ITS) was amplified. The primer pair used

167 for the ITS amplification was based on the sequences published by Navajas et al.

168 (1999), but we modified them slightly for better annealing (forward:

169 5’- AGTCGTAACAAGGTTTCCGTAG-3’; reverse: 5’- GGGGGTAATCGCACTTGA

170 TTTC-3'). Additionally, the gene coding for the Large Subunit of the rRNA (LSU) was

171 amplified partly using the universal primer pair LSU-D1D2.fw2 and LSU-D1D2.rev2

172 (Sonnenberg et al., 2007). Amplification was performed with 30 thermocycler cycles.

173 PCR products were purified either by a polyethylene glycol (PEG)-based method or

174 enzymatically with ExoSAP-IT ${ }^{\mathrm{TM}}$ (ThermoFisher). We sent PCR products to Macrogen

175 Europe Inc. (Amsterdam, The Netherlands) for forward and/or reverse Sanger

176 sequencing. 


\section{Identification of genetic clusters}

178 The COI, ITS, and/or LSU sequences of 230 Poecilochirus samples were aligned gene-

179 wise using default settings of the Geneious Prime implementation MAFFT v.7.450

180 (Katoh \& Standley, 2013). Alignments were concatenated to a supermatrix in which

181 sequences of "N" symbolized missing data/genes. The supermatrix served as input for a

182 phylogenetic analysis with IQtree multicore version 1.6.12 (Nguyen et al., 2015). IQtree

183 estimates maximum-likelihood (ML) phylogenies using a fast and effective stochastic

184 search algorithm. We used IQtree's model finder (Kalyaanamoorthy et al., 2017) to

185 select accurately best-fitting evolutionary models for each gene of the supermatrix. The

186 models TPM2u+F+I+G4, TIM3+F+G4, and HKY+F+G4 were chosen for the COI, ITS,

187 and LSU gene block, respectively. The phylogenetic analysis ran with 10,000 bootstrap

188 replicates using the ultra-fast bootstrap approximation for branch support (Minh et al.,

189 2013), and with a parametric approximate likelihood-ratio test (SH-aLTR) testing the

190 null hypothesis that assumes inferred branches with a length of 0 (Anisimova et al.,

191 2011). We set $P$. subterraneus as outgroup. The phylogenetic tree was visualized with

192 FigTree version 1.4.4 and edited using Inkscape 1.0.1. We also used the "Poisson Tree

193 Process" (PTP) model implemented in the tool multi-rate (m)PTP version 0.2.4 (Kapli

194 et al., 2017). The model is a tree-based approach for species delimitation. It suggests the

195 most likely number of species based on maximum likelihood and a Markov Chain

196 Monte Carlo (MCMC) algorithm to provide support values for each putative species

197 clade. Initially, the minimum branch length was calculated (--minbr_auto) based on the

198 input alignment. In a second step the resulting values and the phylogenetic tree were

199 input to the main mPTP analysis with the following parameters: --mcmc 100,000,000; --

200 mcmc_sample 10,000; --mcmc_burnin 500,000; --mcmc_runs 4; --mcmc_startrandom.

201 To illustrate the geographic distribution of the identified genetic clusters, the $\mathrm{R}$ 202 packages maptools v1.0-2 and scatterpie v0.1.5 (R Core Team, 2020) were used to plot 
203 the relative abundance of the different clusters at each locality on a world map. To

204 support cluster delineation, uncorrected p-distances within and between clusters were

205 calculated based on the COI alignment using MEGA version 10.1.7 (Kumar, Stecher,

206 Li, Knyaz \& Tamura, 2018).

\section{Morphological identification}

208 Mite specimens that were not destroyed during DNA extraction $(n=95)$ were mounted

209 and clarified in Heinze-PVA medium and stored in an oven at $50^{\circ} \mathrm{C}$ until total

210 clarification. Morphological and morphometric analyses of mites were performed using

211 differential interference contrast in a compound microscope (Reichert Diavar, Vienna).

212 Identification of mites was based on the key by Hyatt (1980) and the description of $P$.

213 monospinosus by Wise et al. (1988).

\section{Host specificity}

215 Host specificity was calculated as Shannon-Wiener Diversity (H') and Evenness. We

216 performed these calculations for three European and three North American clusters that

217 contained enough samples and host species. In addition, we used a $\chi^{2}$-test to investigate

218 if the frequency of host species occupied by a mite cluster deviates from the overall host

219 species frequency in the same geographical area. The host species frequency was

220 derived from the number of mites that we sequenced from each beetle species;

221 whenever possible, we had selected mites from different beetle individuals.

222 Subsequently, the $\chi^{2}$ value of each cluster $\left(\chi^{2}\right.$ (cluster) $)$ was set in relation to the theoretical

$223 \chi^{2}$ maximum of the respective cluster $\left(\chi^{2}(\max )\right)$. A high quotient of $\chi^{2}{ }_{(\text {cluster })} / \chi^{2}(\max )$ suggests

224 host specificity of the mite clusters for that area. Calculations for the Shannon-Wiener

225 Index and Evenness were performed using the open source spreadsheet tool provided by

226 LibreOffice version 6.2.8.2., and $\chi^{2}$ values were calculated with the $\mathrm{R}$ Stats package 227 v3.6.2. 


\section{Phylogenetic inference}

229 We used 38 samples for which sequences of all three genes were available for

230 phylogenetic analyses. These samples covered 16 of the clusters previously identified.

231 We applied Maximum Likelihood (ML) and Bayesian Inference (BI) approaches and

232 used four different methods for assigning confidence levels to branches - SH-aLRT,

233 ultrafast bootstrapping (UFBoot), standard bootstrapping (SBS), and posterior

234 probability (PP). Phylogenetic analyses were carried out with IQTree (ML;

235 aLRT/UFBoot), RaxML version 8.2.4 (ML; SBS; Stamatakis, 2014), and MrBayes

236 3.2.7a (BI; PP; Ronquist et al., 2012). The input for all analyses is a concatenated

237 alignment generated with Geneious Prime. All analyses were conducted with the data

238 partitioned by gene. Best-fitting substitution models were found using IQtree. Models

239 were adjusted to the most similar substitution model RaxML and MrBayes can

240 integrate. For the IQtree analysis the same parameter settings were used as described

241 above. For the RaxML analysis, we chose the rapid bootstrapping algorithm (-f a) to

242 perform 10,000 bootstrap replicates and ML searches at once (-\# 10,000; -T 20). For our

243 Bayesian approach, all prior parameters of MrBayes except for the model settings were

244 kept at default. We started MrBayes with 1,000,000 generations (ngen=1,000,000

245 samplefreq=5,000; printfreq $=5,000$; diagnfreq $=1,000$ ). Afterwards, parameter values

246 like effective sample size (ESS) were summarized and checked for reliability with

247 Tracer v. 1.7.1 (Rambaut et al., 2018). Trees were summarized with a burn-in of 10\%.

248 All phylogenies and their support values were read and plotted with FigTree.

249 Illustrations and modifications were conducted with InkScape. In all analyses, $P$.

250 subterraneus specimens were used as the outgroup. 


\section{Divergence time analysis}

252 For divergence time analysis, we combined the data of 25 Poecilochirus specimens with

253 additional Mesostigmata taxa (including our own Macrocheles sequences).

254 Poecilochirus samples were chosen by the availability and quality of COI and LSU

255 sequence and covered 12 of the genetic clusters. The complete dataset consists of 40

256 individuals, of which 26 represent the hyporder Parasitiae (one family), 13 the hyporder

257 Dermanyssiae (10 families) and one the infraorder Uropodina (two families), which

258 serves as the outgroup (Supplement Table S2). The analysis was conducted with Beast

259 v. 2.6 .3 (Bouckaert et al., 2019). Beast2 includes the Fossilized-Birth-Death Process

260 model (FBD) which is an extended version of the Birth-Death Process (Stadler, 2010;

261 Stadler et al., 2018). Both models assume that every living lineage can experience

262 speciation at rate $\lambda$ or go extinct at rate $\mu$, but the FBD model allows the treatment of

263 known fossil calibration points as part of the tree prior at node times. Such priors can be

264 set with the graphical user interface Beauti2. We ran Beast2 under the FBD model using

265 fossil data available for five taxa (Supplement Table S3). Monophyly was fixed for

266 samples of the families Parasitidae, Macrochelidae and Digamasellidae, as well as for

267 the infraorder Gamasina, and the superfamilies Dermanyssoidae and Eviphidoidae. Our

268 analysis is based on the COI and LSU genes of which each represents a separate

269 partition. We set the substitution model to be unlinked and determined the GTR and

270 TN93 model for the COI and LSU partition, respectively. The Clock and Tree model

271 were set to be linked and the analysis ran with the Relaxed Clock Log Normal model.

272 We set the five fossil calibration points to the clade nodes where the fossils are assumed

273 to belong, and ran Beast2 with 1,000,000 generations. Trees were stored every 100

274 generations. Stationarity was reached when all ESS values were above 200 and data

275 were equally distributed in Tracer v. 1.7.1. The final divergence time phylogeny was

276 assembled with TreeAnnotator v2.6.3 (included in Beast2 package) using a burn-in of 
$27710 \%$ and the maximum clade credibility as target tree type. Results were plotted using

278 FigTree and edited with InkScape.

\section{Biogeography and ancestral-area estimation}

280 The divergence time reconstruction was the basis for a biogeographical analysis. We

281 used the R package BioGeoBears (Matzke, 2014) which performs inferences of 282 biogeographic histories on phylogenies. With BioGeoBears, different models of how

283 biogeography may evolve on phylogenies can be tested on a given dated tree. Currently

284 the package includes the Dispersal-Extinction-Cladogenesis model (DEC), a likelihood

285 version of the Dispersal-Vicariance model (DIVALIKE) and the Bayesian Analysis of

286 Biogeography (BAYAREALIKE). Moreover, it provides an extended version for the

287 models by the consideration of additional free parameters like 'j’ (“jump dispersal”) or

288 ' $\mathrm{x}$ ' (geographical distances) while modeling. The "jump dispersal” parameter simulates

289 the founder-event speciation. It describes that at the time of cladogenesis one daughter

290 lineage inherits the ancestral range, and the other lineage occupies a new area through a

291 rare, long-distance colonization event and founds an instantly genetically isolated 292 population (Matzke, 2014; Zhang et al., 2017). Since the biogeography of Poecilochirus

293 is our focus, we pruned the dated tree to a subset containing only Poecilochirus

294 specimens (excl. P. subterraneus) and used it for the BioGeoBears analysis. We divided

295 the Northern Hemisphere in 6 areas: Western North America (W), Eastern North

296 America (N), Europe (E), Northern Asia + Japan (A), Southern Asia (S), and South East

297 Asia ranging to the Solomon Islands (I). In an initial analysis, we tested whether the 298 existence of only the Bering Land Bridge (BLB) or the North Atlantic Land Bridge 299 (NALB) and the BLB might fit the data better. Three model types were tested in three 300 different versions for each scenario (M0=DEC, DIVALIKE, BAYAREALIKE; $301 \mathrm{M} 1=\mathrm{DEC}+\mathrm{J}$, DIVALIKE $+\mathrm{J}$, BAYAREA $+\mathrm{J}$, and $\mathrm{M} 2=\mathrm{DEC}+\mathrm{J}+\mathrm{X}$, DIVALIKE $+\mathrm{J}+\mathrm{X}$, 
302 BAYAREA $+\mathrm{J}+\mathrm{X}$ ), and the likelihood and Akaike Information Criterion with sample

303 correction (AICc) were compared between both scenarios. We continued with the

304 scenario showing the highest likelihood (lowest negative log likelihood value: -lnL) and

305 lowest AICc values in most of the models and compared nested models using a

306 Likelihood Ratio Test (same model type: M0 vs. M1 and M1 vs. M2). The AICc was

307 used to compare among model types (DEC vs. DIVALIKE).

308 A more likely scenario is obtained by running the biogeographical models under a time-

309 stratified analysis. In such an analysis, BioGeoBears can take into account geographical

310 changes and different difficulty levels for dispersal occurring over time. Our time-

311 stratified analysis included three time slices. We tried to represent the geographic

312 conditions of the Eocene/Oligocene, the Miocene, and present conditions. For this

313 scenario we ran the models DEC/DEC+J and DIVALIKE/DIVALIKE+J. 


\section{Results}

\section{Sequence data}

316 We obtained 429 DNA sequences after editing and quality-checking. Of these, 193 COI,

317136 ITS, and 79 LSU sequences belonged to mites that resemble P. carabi, 10 COI, 6

318 ITS, and 3 LSU sequences belonged to P. subterraneus, and one COI and one LSU

319 sequence were generated from two Macrocheles specimens (Supplement Table S1).

320 These sequence data have been submitted to GenBank under the accession numbers

321 MW890765 - MW890966 (COI), MW893012 - MW893060 and MW893063 -

322 MW893153 (ITS), and MW893154 - MW893193 and MW893196 - MW893239

323 (LSU). The average length of the COI, ITS and LSU sequences are 655bp, 509bp and

324 645bp, respectively. All sequences that were blasted against the NCBI database

325 matched published sequences from either Poecilochirus or Parasitidae, with low E-

326 values and a sequence coverage $>70 \%$. Macrocheles samples matched with sequences

327 from M. nataliae.

\section{Identification of genetic clusters}

329 We identified 24 different genetic clusters by the IQtree approach that was based on a

330 concatenated supermatrix of the COI, ITS, and LSU genes obtained from 230

331 Poecilochirus mites (Table 1, Supplement Figure S2). Of these, 3 were clusters in the

332 outgroup $P$. subterraneus. The largest cluster in the ingroup consisted of 89 samples

333 (Europe-1), and seven clusters were represented by only one mite individual (=

334 singletons). Depending on the cluster, the number of different host species ranged from

3351 to 8 , and the number of sampling locations varied from 1 to 13 (Table 1 ). 
Table 1: List of genetic clusters of Poecilochirus. The number of mite individuals, the host species with the number of mite individuals sequenced from each host species, and the country of occurrence with the number of its different localities are listed for each cluster.

\begin{tabular}{|c|c|c|c|}
\hline & $\begin{array}{l}\text { no. of } \\
\text { mites }\end{array}$ & $\begin{array}{l}\text { host species } \\
\text { (no. mites found on each host } \\
\text { species) }\end{array}$ & $\begin{array}{l}\text { country of origin } \\
\text { (no. of different sampling } \\
\text { locations) }\end{array}$ \\
\hline \multicolumn{4}{|l|}{ Clusters } \\
\hline Asia-1 & 6 & N. nepalensis (6) & Taiwan (1) \\
\hline Asia-2 & 11 & $\begin{array}{l}\text { N. concolor (1), N. melissae (1), } \\
\text { N. nepalensis (2), N. schawalleri (2), } \\
\text { N. sinensis (2), N. smefarka (2), } \\
\text { N. vespilloides (1) }\end{array}$ & $\begin{array}{l}\text { China (1), Russia (1), } \\
\text { Taiwan (1), } \\
\text { India (1) }\end{array}$ \\
\hline Asia-3 & 4 & N. melissae (1), N. nepalensis (3) & India (1), China (1) \\
\hline Canada & 2 & N. hybridus (2) & Canada (1) \\
\hline Ecuador & 2 & N. didymus (2) & Ecuador (1) \\
\hline Eurasia & 6 & $\begin{array}{l}\text { N. investigator (2), N. vespillo (1), } \\
\text { N. vespilloides (1) }\end{array}$ & Japan (1), Latvia (1) \\
\hline Europe-1 & 89 & $\begin{array}{l}\text { N. humator (12), N. interruptus (6), } \\
\text { N. investigator (6), N. vespillo (2), } \\
\text { N. vespilloides (62), Pterostichus } \\
\text { melanarius (1) }\end{array}$ & $\begin{array}{l}\text { Germany (7), England (1), } \\
\text { Austria (1), } \\
\text { France (1), Scotland (1), } \\
\text { The Netherlands (1), Poland } \\
(1)\end{array}$ \\
\hline Europe-2 & 27 & $\begin{array}{l}\text { N. humator (1), N. interruptus (6), } \\
N . \text { lunatus (1), N. vespillo (16), } \\
N . \text { vespilloides (3) }\end{array}$ & $\begin{array}{l}\text { Germany (3), Poland (1), } \\
\text { Kazakhstan (1), France (1), } \\
\text { Latvia (1), The Netherlands } \\
\text { (1), Austria (1) }\end{array}$ \\
\hline Europe-3 & 10 & $\begin{array}{l}N . \text { antennatus (2), N. germanicus (2), } \\
N . \text { humator (3), N. interruptus (2), } \\
N . \text { vespilloides (1) }\end{array}$ & $\begin{array}{l}\text { Czech Rep (1), France (1), } \\
\text { Austria (1), England (1) }\end{array}$ \\
\hline Japan & 3 & N. quadripunctatus (3) & Japan (1) \\
\hline $\begin{array}{l}\text { North } \\
\text { America }\end{array}$ & 31 & $\begin{array}{l}\text { N. defodiens (8), N. hebes (2), } \\
N . \text { investigator (6), N. nigrita (2), } \\
\text { N. orbicollis (4), N. sayi (3), N. } \\
\text { tomentosus (4), N. vespilloides (2) }\end{array}$ & USA (6), Canada (2) \\
\hline USA-1 & 13 & $\begin{array}{l}\text { N. orbicollis }(7), N . \text { pustulatus }(1) \\
\text { N. tomentosus }(5)\end{array}$ & USA (3) \\
\hline USA-2 & 6 & N. pustulatus (6) & USA (2) \\
\hline USA-3 & 5 & N. carolina (5) & USA (1) \\
\hline \multicolumn{4}{|l|}{ Singletons } \\
\hline PH-N.apo & 1 & N. apo & Philippines \\
\hline IND-N.ins & 1 & N. insularis & Indonesia (Bali) \\
\hline SI-N.kie & 1 & N. kieictus & Solomon Islands \\
\hline IDN-N.cha & 1 & N. charon & Indonesia (Sulawesi) \\
\hline $\mathrm{CH}-\mathrm{N} . j a p$ & 1 & N. japonicus & China (Liaoning) \\
\hline RUS-N.mor & 1 & N. morio & Russia \\
\hline CH-N.con & 1 & N. concolor & China (Sichuan) \\
\hline \multicolumn{4}{|c|}{ Outgroup P. subterraneus } \\
\hline Psub-NA & 5 & N. sayi (5) & Canada (1); USA (1) \\
\hline Psub-GER1 & 5 & N. humator (5) & Germany (1) \\
\hline Psub-GER2 & 2 & N. humator (2) & Germany (1) \\
\hline
\end{tabular}


336 We named the clusters according to their main distribution area. All clusters but Asia-2

337 were represented by reliable branch support values (SH-aLRT > 80\%; UFBoot > 95\%).

338 The separation of Asia-1, IDN-N.ins and Asia-2 from the remaining singletons resulted

339 in less confident values $(\mathrm{SH}-\mathrm{aLRT}=26 \%$; UFBoot=53\%). However, the close

340 relationships among Asia-1, Asia-2, IDN-N.ins, PH-N.apo and SI-N.kie were well

341 supported as a monophyletic group (SH-aLRT=81.6\%; UFBoot=95\%). Its sister group

342 is a clade formed by the North America and Eurasia clusters but with lower branch

343 support values (SH-aLRT=71.8\%; UFBoot=91\%). Branch support values of deeper

344 phylogenetic splits varied highly (SH-aLRT: 20.7--99.9\%; UFBoot: 67-100\%)

345 indicating a more fragile tree topology (Supplement Figure S2).

346 The mPTP species delimitation results were similar to those of the IQtree approach. The

347 four independent MCMC runs yielded the highest frequencies for species numbers

348 between 22 and 26 with the highest likelihood score for a multi-coalescent rate (-

$349 \ln L=1099.35$ ) calculated for 23 species (including 3 P. subterraneus clusters,

350 Supplement Figure S3).

351 Mites in the three $P$. subterraneus clusters were collected in Europe (2 clusters) or

352 North America (Supplement Table S1). The remaining mite clusters were each

353 restricted to one of three major geographical regions (the European, Asian, and

354 American continent). In North America (USA and Canada), five different clusters

355 occurred. While the North America cluster was distributed from Alaska/Canada over the

356 Western to the Eastern USA, the USA-1 cluster was only found in the North-Eastern

357 part of the USA (Illinois, Ohio and Connecticut). The USA-2 cluster was only present

358 in Illinois and Ohio (Middle-Eastern USA), and the USA-3 cluster was restricted to

359 Florida (South-Eastern USA). The Canada cluster only appeared in Calgary/Alberta. In

360 South America the Ecuador cluster was found (Figure 1, Supplement Table S1). 


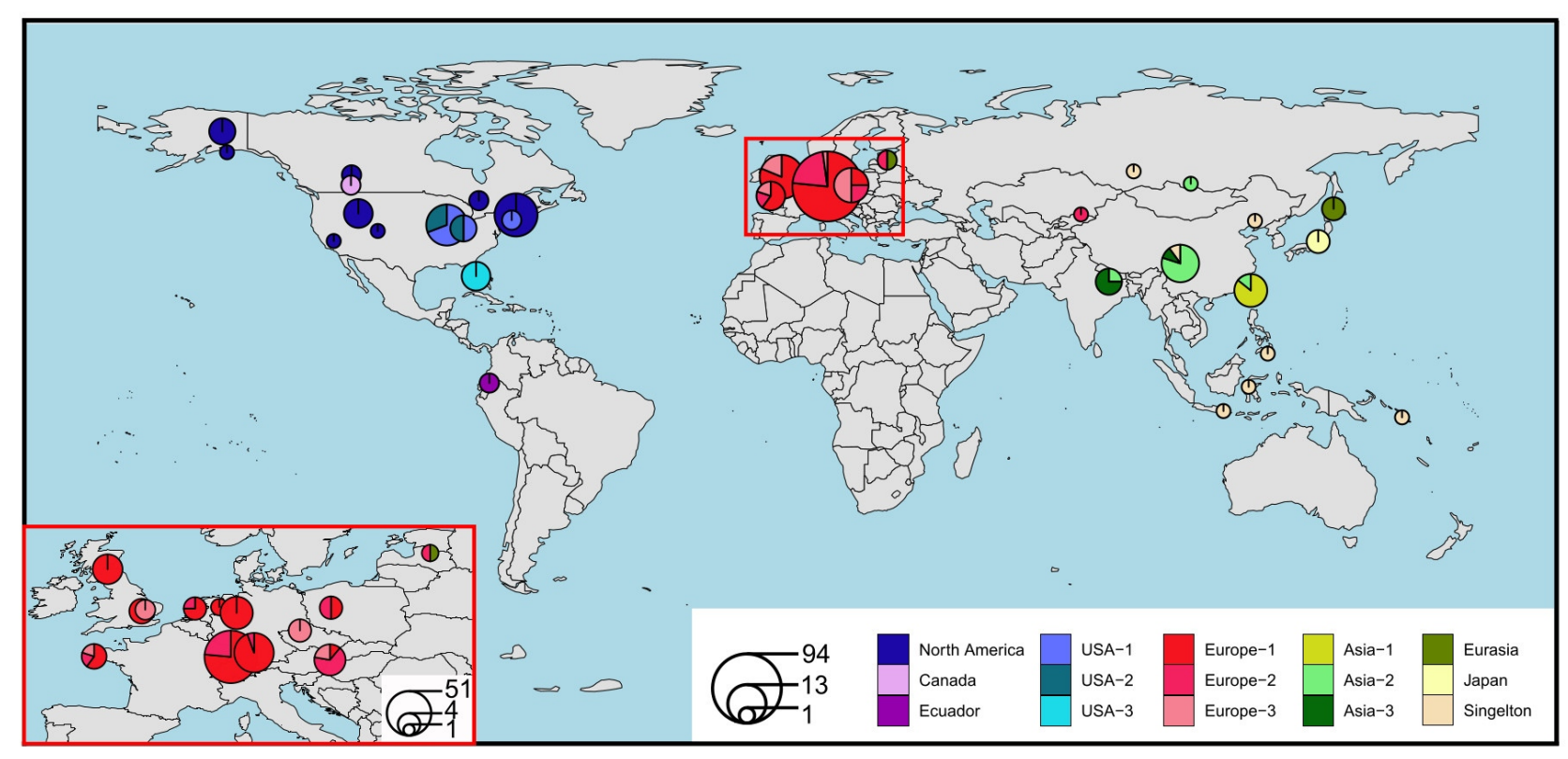

Figure 1: Distribution of the Poecilochirus clusters without $P$. subterraneus. Pie charts show the relative proportion of the different clusters at each location. Each cluster is represented by another color (except singletons) and pie size reflects the sample size at each location. The European distribution is enlarged in the left bottom corner (red rectangle).

361 The clusters Europe-1, Europe-2, and Europe-3 were distributed across Europe whereby

362 the Europe-2 cluster also contained a sample from Kazakhstan. Samples of the Eurasia

363 cluster occurred in Latvia and Japan. All singletons and three additional genetic clusters

364 (Asia-1, Asia-2 and Asia-3) were distributed across the Asian continent. We identified a

365 distinct Japan cluster in addition to the Eurasia cluster on the Japanese Islands

366 (Figure 1).

367 The mean uncorrected p-distance within clusters was $0.78 \%$ ranging from $0.1 \%$ (Asia368 1) to $1.9 \%$ (Asia-3). Among clusters the overall mean p-distance was $15.48 \%$ with a 369 range between 6.03\% (Asia-1/IND-N.ins) and 21.06\% (Psub-GER1/USA-2). The p370 distance between the known species P. carabi s.s. and P. necrophori (Europe-1 vs. 371 Europe-2) was $10.21 \%$, and that between P. carabi/P. necrophori and P. monospinosus 372 (Europe1/Europe2 vs. USA-2/USA-3) was on average 19.46\%. 


\section{Morphological identification}

374 We morphologically identified 95 large Poecilochirus specimens covering 19 different

375 genetic clusters. Of these, 90 specimens from 16 genetic clusters match the $P$. carabi

376 description of Hyatt (1980). The specimens from the Japan cluster differed slightly from

377 Hyatt's description by having a weakly sclerotized body and long podosomal and

378 opisthosomal shields (Supplement Tables S1 and S4).

379 Five specimens were identified as other species: The single intact specimen of the USA-

3802 cluster (sample ID: oh-pus2) corresponded to the description of Poecilochirus

381 monospinosus Wise, Hennessey \& Axtell, 1988. All individuals of the USA-3 cluster

382 resembled $P$. monospinosus as well but differ in the setal pattern. The CH-N.con

383 singleton morphologically resembled Poecilochirus austroasiaticus Vitzhum 1930, but

384 it was larger than reported by Hyatt (1980). These morphological results prompted our

385 definition of P. carabi s.l., which hereafter includes all genetic clusters, except USA-2,

386 USA-3, CH-N.con, and the three P. subterraneus clusters.

\section{Host specificity}

388 We focused on six clusters that contained more than six mite specimens each and that

389 were found in more than one location. Among the three European clusters, Europe-1

390 and Europe-3 were each associated with five, and Europe-2 with four Nicrophorus

391 species, respectively (Table 2; Figure 2). 

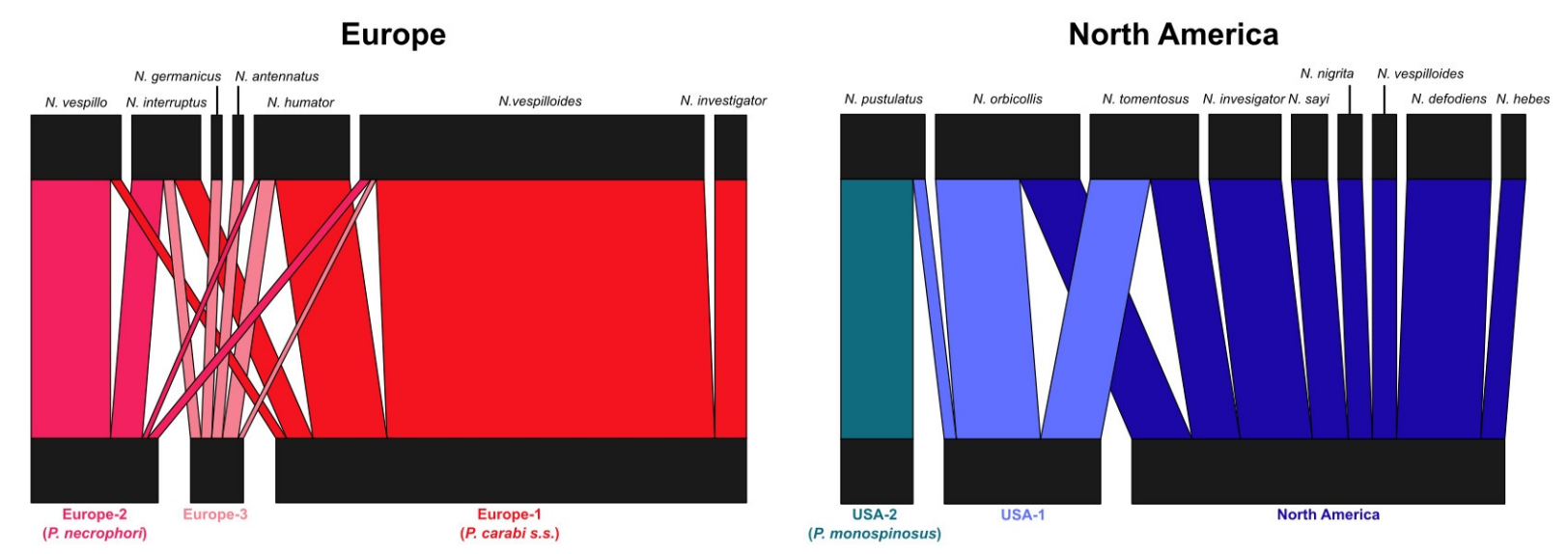

Figure 2: Association network between host species and the six genetic clusters tested for host specificity. The map illustrates the weighted association between mite clusters and Nicrophorus species for the clusters Europe-1, Europe- 2 and Europe-3, as well as the clusters USA-1, USA-2 and North America. The thicker the bars the more mite individuals are associated with the respective host species.

392 Both Shannon-Wiener Diversity Index and Evenness were highest for the cluster

393 Europe-1 and lowest for Europe-3 (Table 2). The association between the three North

394 American clusters and their host species is clearer, even though more host species were

395 involved. The clusters USA-2, USA-1 and North America were found on one, three and

396 eight Nicrophorus species, respectively (Table 2; Figure 2). Furthermore, a similar

397 pattern for both statistical indices was shown in North America where both values

398 decreased from the North America cluster over USA-1 to USA-2. Furthermore, the $x^{2}$

399 ratio ranged from 0.003 to 0.082 in Europe and from 0.014 to 0.256 in North America

400 (Table 2). The higher the quotient, the more the samples from a cluster were

401 concentrated on specific host species. 
Table 2: Host specificity indices for three European $(n=124)$ and three North American $(n=50)$ clusters. The number of mite specimens found on each host, the Shannon Wiener Diversity Index $\left(\mathrm{H}^{\prime}\right)$, Evenness, $x^{2}$-value and $\chi^{2}$-Ratio are listed for each cluster.

\begin{tabular}{|c|c|c|c|c|c|c|c|c|c|c|c|c|c|}
\hline Cluster & \multicolumn{9}{|c|}{ Host species $\dagger$} & \multirow[t]{2}{*}{$\mathbf{H}^{\prime}$} & \multirow{2}{*}{$\begin{array}{c}\text { Even } \\
- \\
\text { ness }\end{array}$} & \multirow{2}{*}{$\underset{\text { (cluster) }}{\mathrm{X}^{2}}$} & \multirow{2}{*}{$\begin{array}{c}\mathbf{X}_{\text {(cluster) }} \\
\mathbf{X}_{(\max )}^{2}\end{array}$} \\
\hline & $\begin{array}{l}\text { N. } \\
\text { vs }\end{array}$ & $\begin{array}{l}\text { N. } \\
\text { vo }\end{array}$ & \multicolumn{2}{|c|}{$\begin{array}{c}\mathrm{N} . \\
\text { hum }\end{array}$} & $\begin{array}{l}\mathrm{N} . \\
\text { int }\end{array}$ & $\begin{array}{l}\text { N. } \\
\text { inv }\end{array}$ & & $\begin{array}{l}\text { v. } \\
\text { nt }\end{array}$ & $\begin{array}{l}\text { N. } \\
\text { ger }\end{array}$ & & & & \\
\hline Europe-1 & 62 & 2 & \multicolumn{2}{|c|}{12} & 6 & 6 & \multicolumn{2}{|c|}{0} & 0 & $\begin{array}{c}0.9 \\
3\end{array}$ & 0.479 & 19.1 * & 0.003 \\
\hline Europe-2 & 3 & 16 & \multicolumn{2}{|c|}{1} & 6 & 0 & \multicolumn{2}{|c|}{0} & 0 & $\begin{array}{c}0.5 \\
4\end{array}$ & 0.277 & 55.0 * & 0.035 \\
\hline \multirow[t]{2}{*}{ Europe-3 } & 1 & 0 & \multicolumn{2}{|c|}{3} & 2 & 0 & \multicolumn{2}{|c|}{2} & 2 & $\begin{array}{c}0.1 \\
5\end{array}$ & 0.076 & 50.3 * & 0.082 \\
\hline & $\begin{array}{l}N . \\
\text { def }\end{array}$ & $\begin{array}{c}\mathrm{N} . \\
\text { heb }\end{array}$ & $\begin{array}{l}N . \\
\text { inv }\end{array}$ & $\begin{array}{l}N . \\
\text { nig }\end{array}$ & $\begin{array}{l}\mathrm{N} . \\
\text { orb }\end{array}$ & $\begin{array}{c}\text { N. } \\
\text { pus }\end{array}$ & $\begin{array}{l}\text { N. } \\
\text { say }\end{array}$ & $\begin{array}{l}\mathrm{N} . \\
\text { tom }\end{array}$ & $\begin{array}{l}\text { N. } \\
\text { vs }\end{array}$ & & & & \\
\hline $\begin{array}{l}\text { North } \\
\text { America }\end{array}$ & 7 & 2 & 6 & 2 & 5 & 0 & 3 & 4 & 2 & $\begin{array}{c}1.5 \\
2\end{array}$ & 0.690 & 10.7 & 0.014 \\
\hline USA-1 & 0 & 0 & 0 & 0 & 7 & 1 & 0 & 5 & 0 & $\begin{array}{c}0.5 \\
8\end{array}$ & 0.266 & 13.9 & 0.045 \\
\hline $\begin{array}{l}\text { USA-2 } \\
\text { (P. } \\
\text { monospinosus) }\end{array}$ & 0 & 0 & 0 & 0 & 0 & 6 & 0 & 0 & 0 & $\begin{array}{c}0.2 \\
5\end{array}$ & 0.116 & 36.9 * & 0.256 \\
\hline
\end{tabular}

402 * significant: $X^{2}$ (cluster) $>$ critical value of $12.59(\mathrm{df}=6 ; \alpha=0.05)$ for the European clusters;

$403 X^{2}$ (cluster) $>$ critical value of $15.51(\mathrm{df}=8 ; \alpha=0.05)$ for the North American clusters

$404 \dagger \mathrm{N}$. vs $=\mathrm{N}$. vespilloides, N. vo $=\mathrm{N}$. vespillo, N. hum $=N$. humator, N. int $=N$. interruptus, N. inv $405=N$. investigator, $\mathrm{N}$. ant $=N$. antennatus, N. ger $=N$. germanicus, $\mathrm{N}$. def $=N$. defodiens, $\mathrm{N}$. heb $406=N$. hebes, N. nig $=N$. nigrita, $N$. orb $=N$. orbicollis, N. pus $=N$. pustulatus, N. say $=N$. sayi, N. 407 tom $=N$. tomentosus

\section{Phylogenetic inference}

409 The tree topologies inferred by the ML (IQtree and RaxML) and BI (MrBayes) analyses

410 were consistent. The phylogeny comprised 37 mite individuals covering 16 genetic

411 clusters. Two P. subterraneus samples served as the outgroup (Figure 3). 


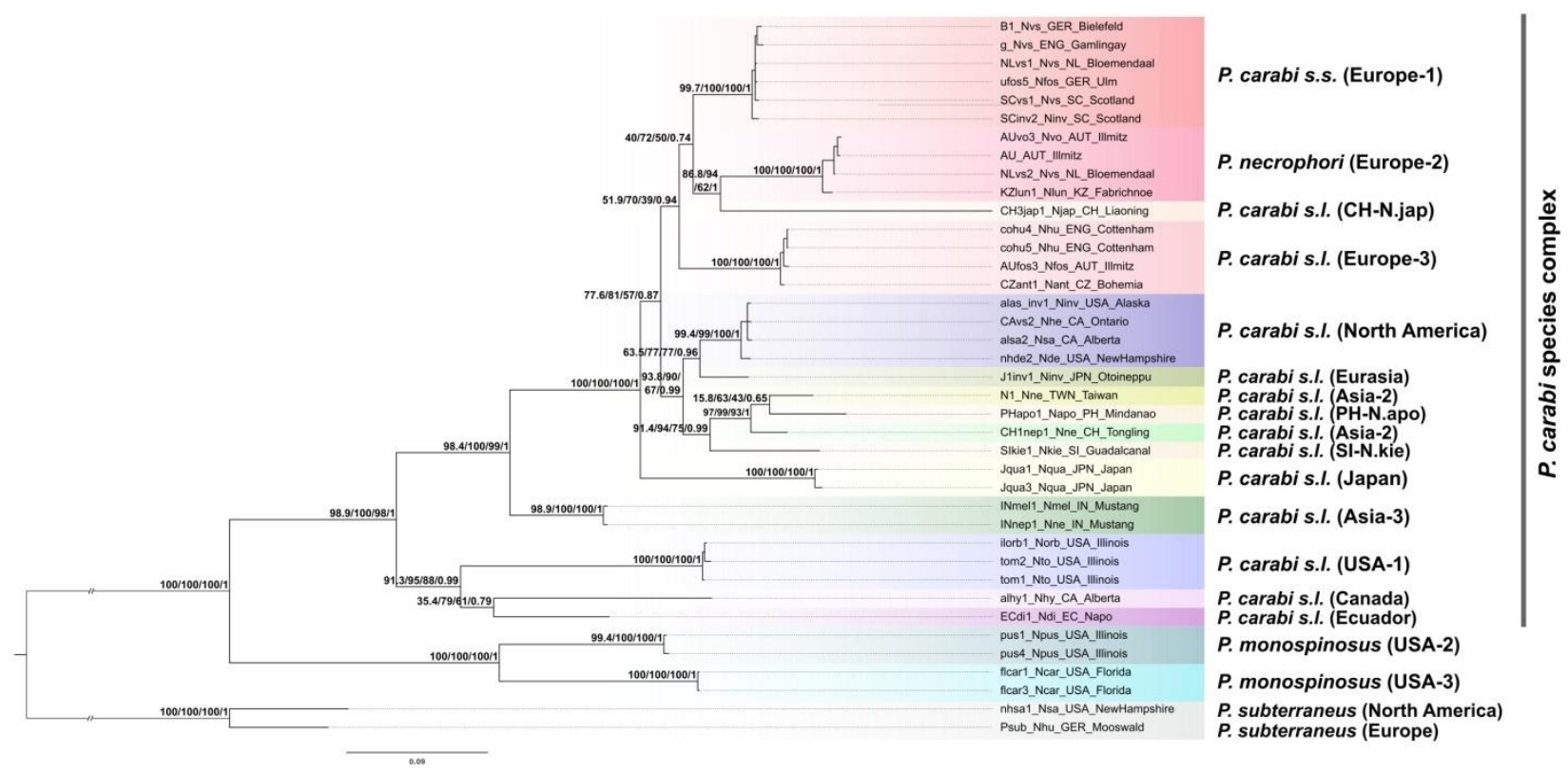

Figure 3: The phylogeny of Poecilochirus carabi s.l. inferred by MrBayes.

Branch labels represent the branch support values obtained by the Likelihood Ratio Test/Ultrafast Bootstrapping/Standard Bootstrapping/Posterior Probability. Genetic clusters are indicated by colors. Basal branches are trimmed and the scale indicates the estimated substitutions per site. Species names are those of the best-fitting species description.

412 Monophyly of the previously defined genetic clusters was confirmed by SH-aLRT,

413 UFBoot; SBS, and PP values. The topology depicted a basal separation into two clades

$414(\mathrm{PP}=1$; aLRT/UFBoot/SBS=100). One clade consisted of mites identified likely as $P$.

415 monospinosus (USA-2 and USA-3), while the other one included all clusters of $P$.

416 carabi s.l.. Within this P. carabi s.l. clade, the most recent common ancestor of the

417 USA-1, Canada, and Ecuador clusters split off first but the close relationship between

418 the Canada and Ecuador cluster showed lower branch support (aLRT=35.4;

419 UFBoot=79; SBS=61; PP=0.79). Subsequently, our tree shows first the Asia-3 and then

420 the Japan cluster branching off, both with high support values ( $\mathrm{PP}=1$;

421 aLRT/UFBoot/SBS>98). The remaining clusters diverged into two clades but this

422 separation was less confident (aLRT=77.6; UFBoot=81; $\mathrm{SBS}=57$; $\mathrm{PP}=0.87$ ). While the

423 close relationship between the North America/Eurasia and the Asian cluster had 
424 consistent support through all but one branch value (aLRT=93.8; UFBoot=90; SBS=67;

$425 \mathrm{PP}=0.99$ ), values within the European/CH-N.jap/RUS-N.mor clade were low and varied

426 among analyses (Figure 3).

\section{Divergence time analysis}

428 The divergence time analysis was based on the COI and LSU gene alignment of 40

429 specimens covering 10 genetic clusters of $P$. carabi s.l., 2 clusters from each $P$.

430 monospinosus and $P$. subterraneus, respectively, and 15 additional Mesostigmata taxa.

431 Certain taxa were represented by chimeric sequences, meaning that the COI and LSU

432 sequences did not originate from the same individual but from the same genus or family

433 (Supplement Table S2).

434 The phylogenetic tree generated by Beast2 had high support values at all but two

435 branches (split between Phytoseiidae and Podocinidae: PP=0.79, and split among Asia-

4362 samples: PP=0.81) (Supplement Figure S4). The relaxed-clock model suggested an

437 origin of the Mesostigmata in the Late Jurassic (156.2 Ma; 95\% credibility intervals

438 [CI] 77 - 272 Ma; Supplement Figure S4) and the divergence into Parasitiae and

439 Dermanyssiae occurred approximately 40 million years later (114.0 Ma; 95\% CI 66 -

$440189 \mathrm{Ma}$ ). Within the Parasitiae clade the first diversification occurred in the early

441 Eocene (53.2 Ma; 95\% CI 26 - $90 \mathrm{Ma}$ ). The segregation of $P$. subterraneus was

442 suggested to occur in the mid Eocene (43.9 Ma; 95\% CI 23 - $74 \mathrm{Ma}$ ). The $P$.

443 monospinosus clade branched off during the transition from the Eocene to the Oligocene

444 (34.7 Ma; 95\% CI 18 - 59 Ma). Diversification of the P. carabi s.l. clade started in the

445 Oligocene with the separation of USA-1 (29.5 Ma; 95\% CI 15 - 50 Ma). All remaining

446 divergence events occurred during the late Oligocene/Miocene ( $5-25$ Ma;

447 Supplement Figure S4). 


\section{Biogeography and ancestral-area estimation}

449 Regarding the first two scenarios we tested (NALB/BLB vs. BLB-only), the

450 NALB/BLB scenario received higher log-likelihood and lower AICc values than the

451 BLB-only scenario in six out of nine models (Supplement Table S5). Hence, our data

452 better fit the assumption that mites dispersed via both the North Atlantic and Bering

453 Land Bridge. As the BAYAREALIKE model type yielded the lowest percentage value

454 of weighted AICc in both of these scenarios ( $<4 \%$; Supplement Table S5), we excluded

455 this model type from further analyses.

456 Within the NALB/BLB scenario, p-values of the LRT were significant when comparing

457 M0 and M1 (DEC: $\mathrm{p}=0.04$; DIVALIKE: $\mathrm{p}=0.04$ ), but were non-significant for the M1

458 and M2 comparison (DEC: $\mathrm{p}=0.06$; DIVALIKE: $\mathrm{p}=0.08$ ). Hence, the more complex

459 model including the parameter " $\mathrm{x}$ " which described the different levels of dispersal

460 difficulties (M2 model) was rejected for both model types.

461 Regarding the weighted AICc values, DEC+J and DIVALIKE+J yielded the highest 462 percentage with 39\% and 45\%, respectively (Supplement Table S6). In the third, the

463 time-stratified scenario, the comparison of nested models resulted in an acceptance of

464 the M1 model in all cases $\left(\mathrm{p}_{(\mathrm{LRT})}<0.05\right)$. The AICc and weighted AICc values were

465 lowest and highest, respectively, for the DIVALIKE+J model (Table 3).

Table 3: Statistics of the BioGeoBears analysis testing four different models in the time-stratified scenario with log likelihood, likelihood ratio test (LRT; $\mathrm{p}(\mathrm{LRT})$ ), sample corrected AIC (AICc) and weighted AICc values.

\begin{tabular}{|c|c|c|c|c|c|c|c|}
\hline model & $-\ln L$ & LRT & $\mathbf{p}_{\text {(LRT) }}$ & AICc & \# param & \# tips & $\begin{array}{c}\text { Weighted } \\
\text { AICc }\end{array}$ \\
\hline DEC & -35.65 & \multirow{2}{*}{4.128} & \multirow{2}{*}{0.04} & 75.47 & 2 & 13 & $26 \%$ \\
\hline $\mathrm{DEC}+\mathrm{J}$ & -33.59 & & & 75.84 & 3 & 13 & $21 \%$ \\
\hline DIVALIKE & -36.5 & \multirow{2}{*}{7.191} & \multirow{2}{*}{0.001} & 77.17 & 2 & 13 & $11 \%$ \\
\hline DIVALIKE+J & -32.91 & & & 74.48 & 3 & 13 & $42 \%$ \\
\hline
\end{tabular}


466 A dispersal rate of $\mathrm{d}<0.001$, an extinction rate of $\mathrm{e}=0.55$, and a relative per-event weight

467 of founder-event speciation of $\mathrm{j}=1.28$ was estimated. The results suggest that dispersal

468 and vicariance as well as founder-event speciation played an important role for the

469 biogeographic pattern of the mites. The most likely ancestral distribution areas of the

470 time-stratified DIVALIKE+J model are visualized in Figure 4. 


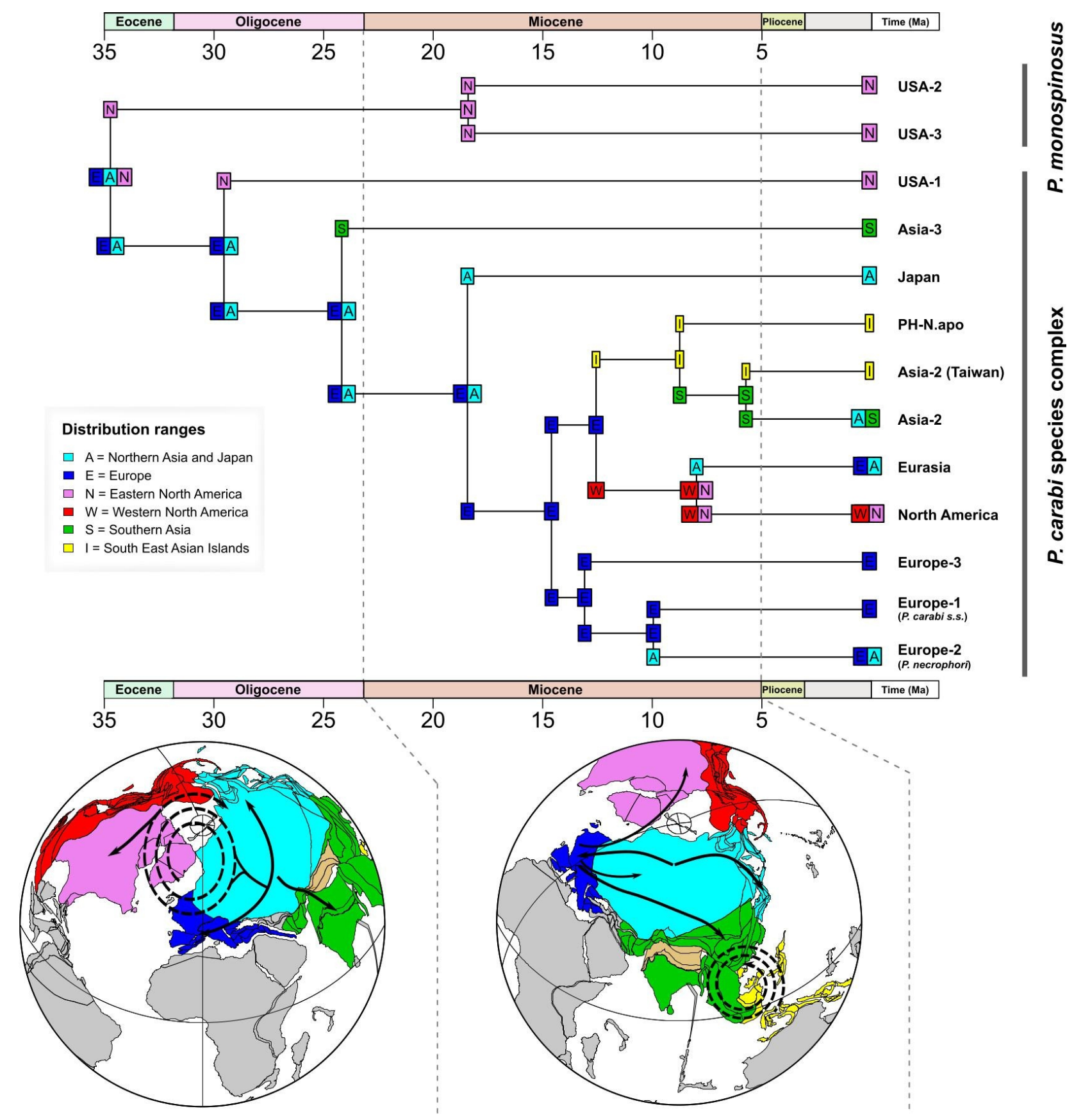

Figure 4: Ancestral state estimation of the DIVALIKE+J model inferred by the time-stratified scenario. Plate tectonic maps are illustrated for $25 \mathrm{Ma}$ and for 12 Ma by the ODSN Plate Tectonic Reconstruction Service

(https://www.odsn.de/odsn/services/paleomap/paleomap.html). Black arrows on the maps show dispersals with and without founder-event speciation.

471 The distribution of the last common ancestor of P. cabi s.l. and P. monospinosus was

472 estimated to range from Eurasia (E and A) to Eastern North America (N). Vicariance

473 was inferred in the branching off of the common ancestor of the USA-2 and the USA-3 
474 cluster $(\mathrm{EAN} \rightarrow \mathrm{EA}+\mathrm{N})$, and of the ancestor of the Japan cluster $(\mathrm{EA} \rightarrow \mathrm{E}+\mathrm{A})$. Six

475 long-distance dispersals with founder-event speciation were suggested to explain the

476 origin of both the USA-1 and the Asia-3 cluster $(\mathrm{EA} \rightarrow \mathrm{EA}+\mathrm{N} ; \mathrm{EA} \rightarrow \mathrm{EA}+\mathrm{S})$, the

477 divergence of the Europe-1/Europe-2 clusters $(\mathrm{E} \rightarrow \mathrm{E}+\mathrm{A})$ and the North

478 America/Eurasia clusters $(\mathrm{WN} \rightarrow \mathrm{WN}+\mathrm{A})$, and two cladogenesis events within the

479 Asian clade $(\mathrm{I} \rightarrow \mathrm{I}+\mathrm{S} ; \mathrm{S} \rightarrow \mathrm{S}+\mathrm{I})$. However, the proportion of the most likely ancestral

480 states deviated just slightly at several cladogenesis events (Supplement Figure S5). 


\section{Discussion}

482 Our study identified 24 distinct genetic Poecilochirus clusters including mites that

483 likely represent four different named species: $P$. subterraneus, $P$. monospinosus, $P$.

484 carabi s.s., and P. necrophori. The phylogenetic and species delimitation analyses

485 indicate that many of the genetic clusters found within these morphological species are

486 likely to be cryptic species, most of which are to our knowledge not formally described.

487 We cannot infer with certainty the geographical origin of Poecilochirus with our data

488 set, but mites appear to have migrated more than once between Asia, Europe and North

489 America. We also found indication that some mite clusters are specialized on particular

490 Nicrophorus species, which may have driven speciation, but this pattern appears to be

491 largely concealed by the effects of multiple migrations between continents. It is difficult

492 to separate these interwoven factors in the evolution of mite species, obfuscating our

493 understanding of the importance of coevolution with hosts and sympatric speciation in

494 Poecilochirus. However, we can state with certainty that all speciation events we could

495 infer happened more than five million years ago, with no indication of recent speciation

496 events or ongoing segregation among extant populations.

\section{Cryptic diversity and host specificity of Poecilochirus mites}

498 Cryptic species have been uncovered by molecular investigations across many mite 499 groups (Beaurepaire et al., 2015; Knee, Beaulieu, Skevington, Kelso, \& Forbes, 2012;

500 Knee et al., 2012; Schäffer \& Koblmüller, 2020) and based on our molecular analyses,

501 we propose that $P$. carabi s.l. consists of at least 17 genetic clusters. Genetically, 502 samples within each cluster are very similar (p-distance $<2 \%$ ), but clusters differ 503 clearly and consistently from each other with a COI divergence of at least $6 \%$ between 504 clusters. Given that the well-studied biological species P. necrophori and P. carabi s.s. 
505 (Baker \& Schwarz, 1997; Müller \& Schwarz, 1990; Nehring et al., 2017) are relatively

506 closely related within P. carabi s.l. and diverge by $10.21 \%$ in their COI sequences, we

507 suggest that most of the genetic clusters that we document, at least those for which we

508 sequenced enough replicates (e.g. Europe-3 or North America), represent separate

509 biological species, most of which are undescribed.

510 Poecilochirus subterraneus

511 Poecilochirus subterraneus served as the outgroup in our study. The species has

512 previously been observed in Europe (mostly on different Nicrophorus species; Hyatt,

513 1980; Korn, 1983), North America (N. investigator, N. nigrita; Grossman \& Smith,

514 2008; Sikes et al., 1996), and Asia (N. quadripunctatus, Satou et al., 2000). Here, we

515 sequenced American and European mites resembling the $P$. subterraneus description

516 and found that while mites from both continents clustered together in our dataset, they

517 segregated into three distinct clusters, one from North America and two from Europe.

518 While species delimitation may be unreliable because of limited sampling among the $P$.

519 subterraneus clusters, our data indicate that $P$. subterraneus might be more diverse than

520 previously thought.

\section{The clades $\boldsymbol{P}$. monospinosus (USA-2 \& USA-3) and}

\section{$522 \quad$ P. cf. austroasiaticus (CH-N.con)}

523 The mites that morphologically resemble the description of $P$. monospinosus fall into

524 two separate genetic clusters that we found on two different host species. USA-3 $(n=5)$

525 have been sampled from $N$. carolina in Florida only. We did not have any samples

526 available from other beetle species in Florida, thus we cannot speculate about any

527 potential specialization on N. carolina.

528 We found USA-2 mites only associated with $N$. pustulatus. This host association

529 persisted across two locations. In both, $N$. pustulatus occurs sympatrically with other 
530 host species ( $N$. orbicollis, $N$. tomentosus). In our data set, only one mite from another

531 genetic cluster was found on $N$. pustulatus. USA-2 was also the cluster with the second

532 lowest Shannon-Wiener index and evenness, and by far the highest $\chi^{2}$ ratio, a measure

533 that takes into account the sampling data quality of the cluster in question. USA-2 thus

534 appears to be a strict monospecific host specialist on $N$. pustulatus. Nicrophorus

535 pustulatus has a unique ecology; it has been reported to reproduce on snake eggs and in

536 bird nests on dead nestlings, and it occurs predominantly in the forest canopy, while

537 other Nicrophorus species are typically found near the ground (DeMarco \& Martin,

538 2020; Smith et al., 2007; Wettlaufer et al., 2018). Nicrophorus pustulatus thus occupies

539 a distinct ecological niche that may isolate the mites, and possibly select for adaptations

540 specific to this niche. Other families of phoretic mites associated with $N$. pustulatus

541 showed no apparent host specificity for this beetle species (Knee, 2017; Knee et al.,

542 2012), indicating that this beetle's unique niche has not caused mite divergence in every

543 case. Previously, P. monospinosus had only been described from poultry manure,

544 preying on fly eggs and larvae - it has not been documented on beetle hosts (Wise et al.,

545 1988). This begs the question whether mites of the original description are an aberrant

546 lineage without beetle association or whether $P$. monospinosus is more general in its

547 host usage and occurs with and without beetles.

548 The mite individual from $N$. concolor found in Central China (Sichuan Province) is

549 particularly interesting because morphologically it resembles $P$. austroasiaticus more

550 than $P$ carabi s.s. or any other described species. A discovery of this species in Central

551 China and the association with $N$. concolor is an unexpected observation as so far $P$.

552 austroasiaticus has only been recorded in Siberia/Northwestern China and Europe on

553 animal corpses, or in association with silphid beetles including $N$. investigator (Hyatt,

554 1980; Makarova, 2013). According to the phylogenetic approach of cluster 
555 identification (IQtree analysis), this singleton is closely related to the clade of $P$.

556 monospinosus (Supplement Figure S2).

\section{The European clusters: P. carabi s.s., P. necrophori, and a new clade}

558 We found three clusters that are almost exclusively distributed in Europe and are closely

559 related. We can unequivocally assign the clusters Europe- 1 and Europe-2 to the species

$560 P$. carabi s.s. and $P$. necrophori because we tested the host preference of some mites

561 before killing them (Schwarz, 1996). Based on their association with different beetle

562 species, these mite clusters appear to either prefer or to avoid certain hosts, which is in

563 agreement with observations on the host range of the two reproductively isolated mite

564 species (Müller \& Schwarz, 1990; Nehring et al., 2017; Schwarz, 1996; Schwarz et al.,

565 1998). Several Nicrophorus species occur sympatrically in Europe, and most of them

566 overlap in their seasonal reproductive period but differ in seasonal and diel activity and

567 habitat use (Dekeirsschieter et al., 2011; Esh \& Oxbrough, 2021; Majka, 2011; Müller

568 \& Eggert, 1987; Schwarz \& Koulianos, 1998; Scott, 1998). Thus, as earlier work

569 already suggested (Schwarz, 1996), the European mite generalist (Europe- $1=P$. carabi

570 s.s.) exploits several host species with different life history traits, while $P$. necrophori

571 (= Europe-2) is specialized on N. vespillo, which prefers open area habitats where other

572 Nicrophorus species are less abundant (Esh \& Oxbrough, 2021).

573 We found a third cluster of mites from across Europe: Europe-3. At the moment, this

574 cluster is a curious case because it is widespread across Europe but was not found in

575 Germany, where most of our samples were collected. The three European clusters were

576 found in sympatry in some locations (France, Austria), indicating that they do not

577 necessarily competitively exclude each other. Sun and Kilner (2019) described a $P$.

578 carabi s.l. population from the United Kingdom that differs in its phenotype from $P$.

579 carabi s.s.. While this population may correspond to P. necrophori, it is tempting to 
580 speculate that it is in fact our Europe-3 cluster, given that we did not find any $P$.

581 necrophori among the 16 mites from the UK.

\section{American samples of $\boldsymbol{P}$. carabi s.l.}

583 The ecology and behavior of the North American P. carabi s.l. is quite well studied,

584 although not to the same extent as the European populations. Brown \& Wilson (1992)

585 reported two reproductively isolated populations from Michigan that differed in

586 morphology, and their preference for host species of Nicrophorus. We were not able to

587 obtain any reference samples from Michigan but our analysis confirms the occurrence

588 of at least two genetic clusters from Northeastern America (USA-1, North America) in

589 addition to $P$. monospinosus. We also found evidence for further clusters from Canada

590 and South America.

591 The North America cluster was the most diverse in terms of host species numbers, and

592 the cluster did not appear to prefer any specific host species among those occurring

593 across its distribution range. Such a broad host range increases the independence of host

594 abundance, seasonal and diel activity, and other life history traits. In comparison, USA-

5951 was found almost exclusively on $N$. orbicollis and $N$. tomentosus in the northeastern

596 USA, which might be an indication of local specialization on two host species. Being a

597 local specialist on two sympatric Nicrophorus beetles with different seasonal activity

598 (Brown \& Wilson, 1992; Keller et al., 2019; Scott, 1998; Wilson, 1982) could expand

599 the reproductive period of the mites.

600 Some previously described populations of $P$. carabi s.l. from Michigan indeed

601 reproduced successfully using various host species, but others were local specialists

602 (Brown \& Wilson, 1992, 1994; Wilson, 1982). In our data, we found no evidence of any

603 clusters being strict specialists for either $N$. orbicollis or $N$. tomentosus, as had been

604 reported by Brown and Wilson (1992) for the Michigan populations. While it is possible 
605 that these Michigan populations belong to genetic clusters that we did not sample, it

606 may also be that genetic clusters are specialists in one community and less strict in their

607 host choice in another (Brown \& Wilson, 1992).

\section{Asian diversity}

609 Our Asian samples cover a great number of sampling locations and host species, but we

610 could only analyze a few or one replicate individuals for most of the genetic clusters.

611 Thus, any ecological inference is impossible and we may have only scratched the

612 surface of the biodiversity of Poecilochirus mites that use Nicrophorus as hosts in Asia.

\section{Phylogenetic inference}

614 Our phylogeny provides a basic overview of the relationships among Poecilochirus

615 mites. Maximum likelihood and Bayesian Inference analyses reveal congruent tree

616 topologies without polytomous relationships among the clusters. We applied different

617 branch support methods (SH-aLRT, UFBoot, SBS, PP) as their accuracy is debated and

618 confidence levels can vary (Anisimova et al., 2011; Pyron et al., 2011). Relationships

619 between clusters are resolved at deeper levels and in some derived clades, as indicated

620 by well-supported branches across all methods. Support values of a medium range $(50<$

621 SH-aLRT/UFBoot/SBS $<$ 75; $0.5<\mathrm{PP}<0.75)$ occur mainly in more derived

622 relationships and reveal higher values for posterior probabilities than for bootstrap

623 approximations. Such deviations occur because bootstrap values are a more

624 conservative support measure than Bayesian posterior probabilities which can produce a

625 higher false-positive rate (Anisimova et al., 2011; Cummings et al., 2003; Erixon et al.,

626 2003). According to the variation of support values at some branches, certain

627 phylogenetic relationships between European, Asian, and North American clusters

628 should be interpreted with caution. Low support values could result from

629 inconsistencies between the gene trees as we used a concatenated supermatrix of COI, 
630 ITS, and LSU, with a partitioning approach. Branch lengths are analogous across the

631 analyses and express an adequate amount of genetic change between internal nodes.

632 Certain branches are in fact relatively long (e.g., USA-2, USA-3 and CH-N.jap). This

633 high level of genetic change could be due to an accelerated rate of evolution, a high

634 extinction rate leaving only one member of a radiation, or an underrepresented diversity

635 caused by incomplete taxon sampling.

636 However, the congruent tree topology inferred by all analyses, the medium to high

637 support values, the appropriate branch lengths, and the exclusive dichotomy all indicate

638 a high degree of robustness for this phylogeny. The genes we concatenated for this

639 phylogenetic reconstruction already provided sufficient genetic information individually

640 to distinguish between morphologically described species in other groups of mites

641 (Lehmitz \& Decker, 2017; Lv et al., 2014; Schäffer \& Koblmüller, 2020). In general,

642 the mites showed low morphological variability, despite their high genetic divergence,

643 but the combined approach of molecular and morphological techniques helps us to

644 better understand the species boundaries and cryptic diversity in this unique group of

645 mites.

\section{Evolutionary history and biogeography}

647 Our data suggest a split between the ancestors of P. carabi s.l. and the P. monospinosus

648 clade during the Eocene/Oligocene and a further radiation within P. carabi s.l. in the

649 Miocene. During this period, most of the Nicrophorus diversity already existed (Sikes

650 \& Vernables, 2013). Although the geographic origin of their common ancestor cannot

651 be stated with certainty, the ancestral area of the $P$. monospinosus clade is clearly the

652 North American continent. Poecilochirus carabi s.l. might have originated in Eurasia

653 with an early dispersal to the New World (USA-1). The likelihood proportions of the

654 most likely ancestral areas differ only slightly at this cladogenesis event (Supplementary 
655 Figure S5), but regardless of ancestral area, the mites moved between the New and Old

656 World during the Eocene/Oligocene. The Miocene diversification of P. carabi s.l. took

657 place in Eurasia with at least one colonization of the New World that is less debatable in

658 terms of dispersal direction (resulting in the North America clade). In both epochs

659 (Eocene/Oligocene and Miocene), a connection between Eurasia and North America by

660 the Bering and North Atlantic land bridges is assumed (Brikiatis, 2014; Denk et al.,

661 2010; Graham, 2018; Jiang et al., 2019; Tiffney, 1985). Although the Bering Land

662 Bridge is often considered the only relevant connection between the continents for floral

663 and faunal migration (Lee et al., 2020; Wen et al., 2016), the assumption that the mites

664 used both land bridges fits our data better. Hence, a closer look at the phylogenetic

665 relationships of beetles and mites occurring near the North Atlantic (e.g., Western

666 Europe; Eastern Canada) would be useful in assessing the role of a North Atlantic Land

667 Bridge and its suitability for the dispersal of small organisms. Regardless of the routes

668 on which the mites migrated between continents, Europe might be a pivotal starting

669 point for their dispersal during the Miocene.

670 In Southern Asia, mites colonized multiple areas. As this region experienced several

671 geological and climatic changes since the early Miocene that could have resulted in the

672 origin of new geographical barriers (e.g., sea level changes and aridification: Bird et al.,

673 2005; Miao et al., 2012; Zhisheng et al., 2001), vicariant speciation might have

674 contributed to the scattered pattern of Asian clusters.

675 We would like to emphasize that models including the "jump dispersal” parameter were

676 most-likely in all biogeographic scenarios, which highlights the importance of founder-

677 event speciation for the evolution of Poecilochirus mites. Furthermore, the results of the

678 tested biogeographic model types DEC $+\mathrm{J}$ and DIVALIKE $+\mathrm{J}$ deviate just slightly among 
679 all analyses. This indicates that dispersal with extinction and vicariance are key

680 processes for understanding the historical biogeography of this species complex.

\section{Drivers of speciation}

682 Based on our phylogenetic analyses, geographic separation is responsible for the main

683 divergence among $P$. carabi s.l. lineages, while the specialization on certain beetle

684 species did not play a significant role on a global scale. Although host-parasite

685 relationships are seen as an important driver of sympatric speciation, co-speciation with

686 the host beetles can be largely ruled out for the Poecilochirus in our study since the

687 main mite diversification happened at least 40 million years after the radiation of the

688 burying beetles ( 75 Ma, Sikes \& Venables, 2013).

689 Because the mites are small and cannot fly, the widely separated distribution areas of

690 the mite clusters are likely due to beetle mobility rather than mite mobility. This may

691 have also facilitated founder events since beetles typically carry several mites, thus

692 increasing the probability that individuals arriving in new areas will be able to find a

693 mate. The holarctic species $N$. vespilloides and $N$. investigator are of particular interest

694 as both species dispersed either from the New to the Old World ( $N$. vespilloides) or vice

695 versa (N. investigator) (Sikes et al., 2008; Sikes \& Venables, 2013). Mites carried by

696 these beetle species appear in multiple genetic clusters, some of which are also closely

697 related (e.g. Eurasia and North America cluster). This suggests that both Nicrophorus

698 species played a major part in the dispersal and evolution of P. carabi s.l..

699 Within the continents, further radiation seems to have taken place, with some lineages

700 specializing on certain hosts (e.g USA-2, Europe-2) and others having a broader host

701 range (Europe-1, North America). In this context, European populations may have

702 radiated in sympatry. Their hosts use different microhabitats to which the mites may

703 have adapted. For example, $N$. vespillo, host to the specialized P. necrophori, is more 
704 common in meadows, while $N$. vespilloides is more abundant in forested areas in

705 Germany, the UK, and Alaska (Majka, 2011; Scott, 1998, Sikes et al., 2016). This may

706 have caused genetic divergence among the mites, both through drift after spatial

707 separation and ecological adaptation. Since meadows are more sun-exposed, $N$. vespillo

708 and its mites may be adapted to warmer temperatures. When kept at the same

709 temperature, $N$. vespilloides develops quicker than $N$. vespillo, which may be the result

710 of countergradient variation across the two species (Conover \& Schultz, 1995; Müller \&

711 Schwarz, 1990). The mites they carry track this difference in their own development

712 time, which may either be a direct adaptation to temperature or an indirect one - because

713 mite development needs to be completed before beetle development for optimal

714 dispersal (Müller \& Schwarz, 1990; Nehring et al 2017; see Brown \& Wilson, 1992 for

715 a similar effect in American populations). Selection on mite development time (e.g. in

716 the event of a host switch) can lead to rapid adaptation in development time and

717 correlated changes in other traits through hitchhiking or pleiotropy (Schedwill et al.,

718 2018). These effects could cause reproductive isolation among the differentially

719 selected mite populations (Nosil \& Harmon, 2009), and thus host specialization can

720 drive genetic divergence. Indeed, a relationship between genetic divergence and host

721 specificity has also been reported from other parasites, such as the honey bee parasite

722 Varroa (Beaurepaire et al., 2015) and Macrocheles species that are associated with

723 Nicrophorus beetles (Knee, 2017). Genetic clustering driven by host adaptation is also

724 found in feather mites that are phoretic on seabirds (Stefan et al., 2018). Host specificity

725 is often seen as a species-level trait. However, it should be considered that local

726 populations of one and the same species could encounter different host communities and

727 may thus specialize on different hosts, an excellent subject for future studies (Brown \&

728 Wilson, 1992; Korallo-Vinarskaya et al., 2009; Thompson, 2009). 


\section{Conclusions}

730 Our global analysis of the $P$. carabi species complex revealed a surprisingly high

731 genetic diversity. Our data support previous ecologically and morphologically defined

732 species clades for $P$. necrophori, $P$. carabi s.s., P. monospinosus, and P. cf.

733 austroasiaticus. In general, phylogenetic relationships between the mite clusters did not

734 match those of the beetles (Sikes \& Venables, 2013).

735 Drivers of genetic diversification differ depending on the geographic scale. Globally, 736 spatial separation between continents can explain the deep splits between clades 737 relatively well, although back-migrations among continents are obvious. Within 738 continents, further diversification appears to have occurred that was independent of 739 separation by oceans (e.g. among Europe 1-3). While this may have happened due to 740 spatial separation on smaller scales that we cannot track, it may have also been driven 741 by ecological factors like adaptation to different host species. Separate mite clusters 742 may evolve in sympatry by ecological adaptation directly to local hosts or to the abiotic 743 environment the hosts live in. The former is most likely for the apparent host specialists

744 that we have identified in our dataset. It is still uncertain in which cases the mites may 745 adapt to the host species or just take any opportunity for dispersal and/or reproduction.

746 However, the close association and occurrence with their beetle hosts shaped the 747 evolution of Poecilochirus mites, and putative drivers depend on the host communities 748 as well as the features of their biotic and abiotic environment.A taxonomic revision of 749 the genus in future investigations would greatly facilitate our understanding of 750 speciation and biogeographic processes in this species complex and genus.

\section{Acknowledgments}

752 We are indebted to all colleagues who sent us mites they had collected: A Barsevskis, M 753 Brandley, J\&I Brookhart, JM Carpenter, L DeCicco, R Enser, J Hajek, B Jarrett, L 
754 Jingke, Z Kaszab, R Kilner, G Kushnak, T Larsen, R Leech, J Longino, R Madge, K

755 Maruyama, M Maruyama, D Mohagan, T Mousseau, JK Müller, P Naskrecki, M

756 Nishikawa, S Peck, J Peck, C Raithel, A Riedel, J Ruzicka, K Sagata, M Schilthuizen,

757 MP Scott, KS Sheldon, H Sipkova, J Smiley, PT Smiseth, RJ Smith, S Steiger, H

758 Sugaya, S Suzuki, M Ulyshen, A Urbański, D Wagner, S Werner, J Withrow, N Wood.

759 For help with expeditions to China, Nepal, and Japan we graciously thank: P Naskrecki,

760 and R Ziedler (China), D Manandhar, and S Peck (Nepal) and S Suzuki, M Ôhara, T

761 Nisimura, M Maruyama, and M Nagano (Japan). Funding to VN was provided by the

762 Freiburg Research Innovation Fund and the German Research Foundation (NE 1969/3-

763 1), and the Rapid Assessment Program (RAP) of Conservation International, a NSERC

764 Discovery grant, a National Science Foundation Grant (DEB-9981381), a University of

765 Connecticut Research Council grant, and a National Geographic Society grant

766 supported DSS’s field work. We thank Karen Meusemann and Josef K Müller for

767 insightful discussions. 


\section{Supplemental information}

769 Supplement Table S1: Overview of single samples with cluster assignment, sampling 770 time and location, host species, country, storage, morphological affiliation, and cluster 771 affiliation.

772 Supplement Table S2: Downloaded COI and LSU sequences of the Mesostigmata taxa 773 with accession number and references. Sequences are used for the divergence time 774 analysis.

775 Supplement Table S3: Fossil data used in the divergence time analysis. Listed are the 776 taxonomic state (superfamily, family and/or genus), age in million years ago [Ma].

777 Supplement Table S4: Morphometric measurements of specimens underwent DNA 778 extraction. Measurements are listed for the podosomal length and width, sternal plate 779 length, opithosomal length, the z1, s1, s2, r3, st4, the macroseta leg IV, and the length 780 of digitus mobilis. All measurements are in $\mu \mathrm{m}$.

781 Supplement Table S5: Comparison table of likelihood and sample corrected Akaike 782 Information Criteria values (AICc) for the NALB/BLB and BLBonly scenarios inferred 783 by the BioGeoBears analysis.

Supplement Table S6: Statistics of the BioGeoBear analysis to test for the best fitting biogeographic model considering the scenario NALB/BLB. Log likelihood values for each model are calculated and nested models (M0 vs. M1 and M1 vs. M2) are tested using the Likelihood ratio test (LRT) with its p-values. Non-nested model comparisons are evaluated by the sample corrected Akaike Information Criteria (AICc).

Supplement Figure S1: Sample distribution. Coloration of the world map indicates the annual temperature obtained from WorldClim data (Bioclimatic variable BIO1 - Annual Mean Temperature, www.worldclim.org). Green shaded areas represent the current distribution area of Nicrophorus and each dot represents one sample locality of the mite sample set. 
794 Supplement Figure S2: Phylogenetic reconstruction of the entire Poecilochirus dataset 795 obtained with IQtree. Branch labels represent SH-aLRT and ultrafast bootstrap values in 796 percentage. High branch support is suggested with SH-aLRT $>=80 \%$ and UFBoot $>=$ 797 95\%. Clades which show short branch length and/or polytomy have been collapsed. 798 Clade/Cluster labels are assigned to the right.

799 Supplement Figure S3: Species delimitation analysis performed with the mPTP tool. 800 The analysis is based on the entire Poecilochirus data set and its resulting IQtree 801 phylogeny. The analysis inferred a total of 23 species (including the $3 P$. subterraneus 802 species). The diagram shows the likelihood distribution of the 4 MCMC runs over 10 803 million iterations.

804 Supplement Figure S4: Time-calibrated tree of the Mesostigmata taxa with the focus 805 on divergence times of the P. carabi species complex generated by Beast2. Represented 806 branch labels indicate posterior probabilities below 0.9 , branches without labeling have 807 support values above 0.9 . The chronogram tree shows mean node ages and node bars 808 represent a 95\% credibility interval. Time scale on the bottom refers to millions of years 809 ago. Red circles depict fossil calibration points.

810 Supplement Figure S5: Illustration of the ancestral state estimation with proportions of 811 all ancestral states at each node depicted as pie charts. Values are calculated with the R 812 package BioGeoBears and represent the results of the DIVALIKE $+\mathrm{J}$ model conducted 813 by the time-stratified analysis. The legend shows all possible ancestral state 814 combinations allowed by the analysis settings.

\section{Author contributions}

816 JC conducted bioinformatic analyses, conceptualized and drafted the manuscript.

817 AKE, WK, DSS edited the manuscript

818 JC, PH, WK, MN, NS conducted molecular wet lab work and initial sequence analyses

819 JB identified and measured mite specimens

820 WH, PH, WK, VN, NS, DSS contributed mite specimens

821 VN conceived and supervised the project, co-wrote the manuscript 


\section{Data Accessibility}

DNA sequences: Genbank accessions MW890765 - MW890966 (COI), MW893012 MW893060 and MW893063 - MW893153 (ITS), and MW893154 - MW893193 and MW893196 - MW893239 (LSU) are provided at NCBI.

\section{References}

Anderson, R. S. 1982. Resource partitioning in the carrion beetle (Coleoptera: Silphidae) fauna of southern Ontario: ecological and evolutionary considerations. Canadian Journal of Zoology 60: 1314-1325.

Anisimova, M., Gil, M., Dufayard, J. F., Dessimoz, C., \& Gascuel, O. (2011). Survey of branch support methods demonstrates accuracy, power, and robustness of fast likelihood-based approximation schemes. Systematic Biology, 60(5), 685-699.

Aoki, J. (1974) On the fossil mites in Mizunami amber from Gifu Prefecture, Central Japan. Bulletin of the Mizunami Fossil Museum, 1, 397-399.

Arribas, P., Andújar, C., Moraza, M. L., Linard, B., Emerson, B. C., \& Vogler, A. P. (2020). Mitochondrial metagenomics reveals the ancient origin and phylodiversity of soil mites and provides a phylogeny of the Acari. Molecular Biology and Evolution, 37(3), 683-694.

Baker, A. S., \& Schwarz, H. H. (1997). Morphological differences between sympatric populations of the Poecilochirus carabi complex (Acari Mesostigmata: Parasitidae) associated with burying beetles (Silphidae: Nicrophorus). Systematic Parasitology, 37, 179-185.

Beaurepaire, A. L., Truong, T. A., Fajardo, A. C., Dinh, T. Q., Cervancia, C., \& Moritz, R. F. A. (2015). Host specificity in the honeybee parasitic mite, Varroa spp. in Apis mellifera and Apis cerana. PLoS ONE, 10(8), 1-12.

Bird, M. I., Taylor, D., \& Hunt, C. (2005). Palaeoenvironments of insular Southeast Asia during the Last Glacial Period: a savanna corridor in Sundaland? Quaternary Science Review, 24(20-21), 2228-2242.

Bouckaert, R., Vaughan, T. G., Barido-Sottani, J., Duchêne, S., Fourment, M., Gavryushkina, A., Heled, J., Jones, G., Kühnert, D., De Maio, N., Matschiner, M., Mendes, F. K., Müller, N. F., Ogilvie, H. A., Du Plessis, L., Popinga, A., Rambaut, A., Rasmussen, D., Siveroni, I., ... Drummond, A. J. (2019). BEAST 2.5: An advanced software platform for Bayesian evolutionary analysis. PLoS Computational Biology, 15(4), 1-28. https://doi.org/10.1371/journal.pcbi.1006650

Brikiatis, L. (2014). The de geer, thulean and beringia routes: Key concepts for understanding early cenozoic biogeography. Journal of Biogeography, 41(6), 10361054.

Brown, J. M. (1989). Specialization in Poecilochirus carabi, a phoretic mite. Michigan State University, East Lansing, Michigan, USA. 
860

Brown, J. M., \& Wilson, D. S. (1992). Local specialization of phoretic mites on sympatric carrion beetle hosts. Ecology, 73(2), 463-478.

Brown, J. M., \& Wilson, D. S. (1994). Poecilochirus carabi: Behavioral and LifeHistory Adaptations to Different Hosts and the Consequences of Geographical Shifts in Host Communities. In M. A. Houck (Ed.), Mites: Ecological and Evolutionary Analyses of Life-History Patterns (1st ed., pp. 3-22). Capman \& Hall Inc.

Burke, K., Wettlaufer, J., Beresford, D., \& Martin, P. (2020). Habitat use of cooccurring burying beetles (genus Nicrophorus) in southeastern Ontario. Canadian Journal of Zoology, 98(9), 591-602.

Butlin, R., Debelle, A., Kerth, C., Snook, R. R., Beukeboom, L. W., Castillo Cajas, R. F., Diao, W., Maan, M. E., Paolucci, S., Weissing, F. J., van de Zande, L., Hoikkala, A., Geuverink, E., Jennings, J., Kankare, M., Knott, K. E., Tyukmaeva, V. I., Zoumadakis, C., Ritchie, M. G., ... Schilthuizen, M. (2012). What do we need to know about speciation? Trends in Ecology and Evolution, 27(1), 27-39.

Conover, D. O., \& Schultz, E. T. (1995). Phenotypic similarity and the evolutionary significance of countergradient variation. Trends in Ecology and Evolution, 10(6), 248-252.

Cummings, M. P., Handley, S. A., Myers, D. S., Reed, D. L., Rokas, A., \& Winka, K. (2003). Comparing Bootstrap and Posterior Probability Values in the Four-Taxon Case. Systematic Biology, 52(4), 477-487. https://doi.org/10.1080/10635150309311

De Gasperin, O., \& Kilner, R. M. (2015). Friend or foe: Inter-specific interactions and conflicts of interest within the family. Ecological entomology, 40(6), 787-795.

Dekeirsschieter, J., Verheggen, F., Lognay, G., \& Haubruge, E. (2011). Large carrion beetles (Coleoptera, Silphidae) in Western Europe: A review. Biotechnologie, Agronomie, Société et Environnement, 15(3), 435-447.

DeMarco, K. V. B., \& Martin, P. R. (2020). A case of a Pustulated Carrion Beetle (Nicrophorus pustulatus, Coleoptera: Silphidae) burying live Tree Swallow (Tachycineta bicolor, Passeriformes: Hirundinidae) nestlings under the nest. The Canadian Field-Naturalist, 134(3), 217-221.

Denk, T., Grímsson, F., \& Zetter, R. (2010). Episodic Migration of Oaks to Iceland: Evidence for a North Atlantic "Land Bridge" in the latest Miocene. American Journal of Botany, 97(2), 276-287.

Dunlop, J. A., Kontschán, J., Walter, D. E., \& Perrichot, V. (2014). An ant-associated mesostigmatid mite in Baltic amber. Biology Letters, 10(9), 20140531.

Dunlop, J. A., Kontschán, J., \& Zwanzig, M. (2013). Fossil mesostigmatid mites (Mesostigmata: Gamasina, Microgyniina, Uropodina), associated with longhorn beetles (Coleoptera: Cerambycidae) in Baltic amber. Naturwissenschaften, 100(4), 337-344.

Esh, M., \& Oxbrough, A. (2021). Macrohabitat associations and phenology of carrion beetles (Coleoptera: Silphidae, Leiodidae: Cholevinae). Journal of Insect Conservation, 25(1), 123-136. https://doi.org/10.1007/s10841-020-00278-4 
901 Erixon, P., Svennblad, B., Britton, T., \& Oxelman, B. (2003). Reliability of Bayesian

902

903

904

905

906

907

908

909

910

911

912

913

914

915

916

917

918

919

920

921

922

923

924

925

926

927

928

929

930

931

932

933

934

935

936

937

938

Posterior Probabilities and Bootstrap Frequencies in Phylogenetics. Systematic Biology, 52(5), 665-673. https://doi.org/10.1080/10635150390235485

Farish, D. J., \& Axtell, R. C. (1971). Phoresy redefined and examined in Macrocheles muscaedomesticae (Acarina: Macrochelidae). Acarologia, 13(1), 16-29.

Folmer, O., Black, M., Hoeh, W., Lutz, R., \& Vrijenhoek, R. (1994). DNA primers for amplification of mitochondrial cytochrome c oxidase subunit I from diverse metazoan invertebrates. Molecular Marine Biology and Biotechnologiew, 3(5), 294-299.

García-Varela, M., De León, G. P. P., Aznar, F. J., \& Nadler, S. A. (2011). Erection of Ibirhynchus gen. nov.(Acanthocephala: Polymorphidae), based on molecular and morphological data. Journal of Parasitology, 97(1), 97-105.

Graham, A. (2018). The role of land bridges, ancient environments, and migrations in the assembly of the North American flora. Journal of Systematics and Evolution, 56(5), 405-429.

Grossman, J. D., \& Smith, R. J. (2008). Phoretic mite discrimination among male burying beetle (Nicrophorus investigator) hosts. Annals of the Entomological Society of America, 101(1), 266-271.

Hatch, M. H. (1927). Studies on the Silphinae. Journal of the New York Entomological Society, 35, 331-370.

Hirschmann, W. (1971). Fossil mite of the genus Dendrolaelaps (Acarina, Mesostigmata, Digamasellidae) found in amber from Chiapas, Mexico. Calif Univ Publ Entomol.

Hoberg, E. P., Brooks, D. R., \& Siegel-Causey, D. (1997). Host-parasite co-speciation: history, principles, and prospects. In Host-parasite evolution: General principles and avian models (pp. 212-235).

Hunter, P. E., \& Rosario, R. M. T. (1988). Associations of Mesostigmata with Other Arthropods. Annual Review of Entomology, 33(1), 393-417.

Huyse, T., Poulin, R., \& Théron, A. (2005). Speciation in parasites: A population genetics approach. Trends in Parasitology, 21(10), 469-475.

Hyatt, K. H. (1980). Mites of the subfamily Parasitinae (Mesostigma: Parasitidae) in the British Isles. Bulletin of the British Museum (Natural History). Zoology, 38(5), 237378.

Jiang, Y., Gao, M., Meng, Y., Wen, J., Ge, X.-J., \& Nie, Z.-L. (2019). The importance of the North Atlantic land bridges and eastern Asia in the post-boreotropical biogeography of the Northern Hemisphere as revealed from the poison ivy genus (Toxicodendron, Anacardiaceae). Molecular Phylogenetics and Evolution, 139, 106561. https://doi.org/https://doi.org/10.1016/j.ympev.2019.106561 
Kalyaanamoorthy, S., Minh, B. Q., Wong, T. K. F., Von Haeseler, A., \& Jermiin, L. (2017). ModelFinder: fast model selection for accurate phylogenetic estimates. Nature Methods, 14, 587-589.

Kapli, P., Lutteropp, S., Zhang, J., Kobert, K., Pavlidis, P., Stamatakis, A., \& Flouri, T. (2017). Multi-rate Poisson tree processes for single-locus species delimitation under maximum likelihood and Markov chain Monte Carlo. Bioinformatics, 33(11), 16301638. https://doi.org/10.1093/bioinformatics/btx025

Katoh, K., \& Standley, D. M. (2013). MAFFT multiple sequence alignment software version 7: Improvements in performance and usability. Molecular Biology and Evolution, 30(4), 772-780. https://doi.org/10.1093/molbev/mst010

Keller, M. L., Howard, D. R., \& Hall, C. L. (2019). Spatiotemporal niche partitioning in a specious silphid community (Coleoptera: Silphidae, Nicrophorus). Science of Nature, 106(11-12). https://doi.org/10.1007/s00114-019-1653-6

Klimov, P. B., OConnor, B. M., Chetverikov, P. E., Bolton, S. J., Pepato, A. R., Mortazavi, A. L., Tolstikov, A.V., Bauchan, G. R. and Ochoa, R. (2018). Comprehensive phylogeny of acariform mites (Acariformes) provides insights on the origin of the four-legged mites (Eriophyoidea), a long branch. Molecular Phylogenetics and Evolution, 119, 105-117.

Klompen, H., Lekveishvili, M., \& Black IV, W. C. (2007). Phylogeny of parasitiform mites (Acari) based on rRNA. Molecular Phylogenetics and Evolution, 43(3), 936951.

Knee, W. (2017). New Macrocheles species (Acari, Mesostigmata, Macrochelidae) associated with burying beetles (Silphidae, Nicrophorus) in North America. ZooKeys, 721, 1-32. https://doi.org/10.3897/zookeys.721.21747

Knee, W., Beaulieu, F., Skevington, J. H., Kelso, S., Cognato, A. I., \& Forbes, M. R. (2012). Species Boundaries and Host Range of Tortoise Mites (Uropodoidea) Phoretic on Bark Beetles (Scolytinae), Using Morphometric and Molecular Markers. PLoS ONE, 7(10), 1-15. https://doi.org/10.1371/journal.pone.0047243

Knee, W., Beaulieu, F., Skevington, J. H., Kelso, S., \& Forbes, M. R. (2012). Cryptic species of mites (Uropodoidea: Uroobovella spp.) associated with burying beetles (Silphidae: Nicrophorus): The collapse of a host generalist revealed by molecular and morphological analyses. Molecular Phylogenetics and Evolution, 65(1), 276286.

Korallo-Vinarskaya, N. P., Krasnov, B. R., Vinarski, M. V., Shenbrot, G. I., Mouillot, D., \& Poulin, R. (2009). Stability in abundance and niche breadth of gamasid mites across environmental conditions, parasite identity and host pools. Evolutionary Ecology, 23(3), 329-345.

Korn, W. (1982). Zur Fortpflanzung von Poecilochirus carabi G. und R. Canestrini 1882 (syn. P. necrophori Vitzt.) und P. austroasiaticus Vitzthum 1930 (Gamasina, Eugamasidae). SPIXIANA, 5(3), 261-288. 
Kumar, S., Stecher, G., Li, M., Knyaz, C., \& Tamura, K. (2018). MEGA X: molecular evolutionary genetics analysis across computing platforms. Molecular biology and evolution, 35(6), 1547-1549.

Lee, G. E., Condamine, F. L., Bechteler, J., Pérez-Escobar, O. A., Scheben, A., SchäferVerwimp, A., Pócs, T., \& Heinrichs, J. (2020). An ancient tropical origin, dispersals via land bridges and Miocene diversification explain the subcosmopolitan disjunctions of the liverwort genus Lejeunea. Scientific Reports, 10(1), 1-13. https://doi.org/10.1038/s41598-020-71039-1

Lehmitz, R., \& Decker, P. (2017). The nuclear 28S gene fragment D3 as species marker in oribatid mites (Acari, Oribatida) from German peatlands. Experimental and Applied Acarology, 71(3), 259-276. https://doi.org/10.1007/s10493-017-0126-X

Lv, J., Wu, S., Yongning, Z., Chen, Y., Feng, C., Yuan, X., Guangle, J., Junhua, D., Caixia, W., Qin, W., Lin, M., \& Lin, X. (2014). Assessment of four DNA fragments (COI, 16S rDNA, ITS2, 12S rDNA) for species identification of the Ixodida (Acari: Ixodida). Parasites \& Vectors, 7(1), 93.

Magalhães, S., Forbes, M. R., Skoracka, A., Osakabe, M., Chevillon, C., \& McCoy, K. D. (2007). Host race formation in the Acari. Experimental and Applied Acarology, 42(4), 225-238. https://doi.org/10.1007/s10493-007-9091-0

Majka, C. G. (2011). The Silphidae (Coleoptera) of the maritime provinces of Canada. Journal of the Acadian Entomological Society, 7.

Makarova, O. L. (2013). Gamasid mites (Parasitiformes, Mesostigmata) of the European arctic and their distribution patterns. Entomological Review, 93(1), 113133. https://doi.org/10.1134/S0013873813010156

Mašán, P. (1999). Mites (Acarina) associated with burying and carrion beetles (Coleoptera, Silphidae) and description of Poecilochirus mrciaki sp. $n$. (Mesostigmata, Gamasina). Biologia, Bratislava 54, 515-524.

Matzke, N. J. (2014). Model selection in historical biogeography reveals that founderevent speciation is a crucial process in island clades. Systematic Biology, 63(6), 951970.

Meierhofer, I., Schwarz, H. H., \& Müller, J. K. (1999). Seasonal variation in parental care, offspring development, and reproductive success in the burying beetle, Nicrophorus vespillo. Ecological Entomology, 24, 73-79.

Miao, Y., Herrmann, M., Wu, F., Yan, X., \& Yang, S. (2012). What controlled MidLate Miocene long-term aridification in Central Asia? - Global cooling or Tibetan Plateau uplift: A review. Earth-Science Reviews, 112(3-4), 155-172.

Minh, B. Q., Nguyen, M. A. T., \& Von Haeseler, A. (2013). Ultrafast approximation for phylogenetic bootstrap. Molecular Biology and Evolution, 30(5), 1188-1195.

Müller, J. K., \& Eggert, A. K. (1987). Effects of carrion-independent pheromone emission by male burying beetles (Silphidae: Necrophorus). Ethology, 76(4), 297304. 
1019

1020

1021

1022

1023

1024

1025

1026

1027

1028

1029

1030

1031

1032

1033

1034

1035

1036

1037

1038

1039

1040

1041

1042

1043

1044

1045

1046

1047

1048

1049

1050

1051

1052

1053

1054

1055

1056

1057

1058

1059

Müller, J. K., \& Schwarz, H. H. (1990). Differences in carrier-preference and evidence of reproductive isolation between mites of Poecilochirus carabi (Acari, parasitidae) living phoretically on two sympatric Necrophorus species (Coleoptera, silphidae). Zoologische Jahrbücher: Abteilung Für Systematik, Geographie Und Biologie Der Tiere, 117(1), 23-30.

Navajas, M., Lagnel, J., Fauvel, G., \& De Moraes, G. (1999). Sequence variation of ribosomal Internal Transcribed Spacers (ITS) in commercially important Phytoseiidae mites. Experimental and Applied Acarology, 23(11), 851-859. https://doi.org/10.1023/A:1006251220052

Navajas, M., Conte, Y. L., Solignac, M., Cros-Arteil, S., \& Cornuet, J. M. (2002). The complete sequence of the mitochondrial genome of the honeybee ectoparasite mite Varroa destructor (Acari: Mesostigmata). Molecular Biology and Evolution, 19(12), 2313-2317.

Nehring, V., Müller, J. K., \& Steinmetz, N. (2017). Phoretic Poecilochirus mites specialize on their burying beetle hosts. Ecology and Evolution, 7(24), 10743-10751. https://doi.org/10.1002/ece3.3591

Nehring, V., Teubner, H., \& König, S. (2019). Dose-independent virulence in phoretic mites that parasitize burying beetles. International journal for parasitology, 49(10), 759-767.

Nguyen, L. T., Schmidt, H. A., Von Haeseler, A., \& Minh, B. Q. (2015). IQ-TREE: A fast and effective stochastic algorithm for estimating maximum-likelihood phylogenies. Molecular Biology and Evolution, 32(1), 268-274.

Nosil, P., \& Harmon, L. J. (2009). Niche dimensionality and ecological speciation. Speciation and patterns of diversity, 127-154.

Paterson, S., Vogwill, T., Buckling, A., Benmayor, R., Spiers, A. J., Thomson, N. R., Quail, M., Smith, F., Walker, D., Libberton, B., Fenton, A., Hall, N., \& Brockhurst, M. (2010). Antagonistic coevolution accelerates molecular evolution. Nature, 464, 275-278.

Peck, S. B., \& Anderson, R. S. (1985). Taxonomy, phylogeny and biogeography of the carrion beetles of Latin America (Coleoptera: Silphidae). Quaestiones Entomologicae, 21, 247-317.

Perotti, M. A., \& Braig, H. R. (2009). Phoretic mites associated with animal and human decomposition. Experimental and Applied Acarology, 49(1-2), 85-124. https://doi.org/10.1007/s10493-009-9280-0

Ramaraju, K., \& Madanlar, N. (1998). Four new Poecilochirus G. \& R. Canestrini (Acarina: Parasitidae) species from Turkey. Türkiye Entomoloji Dergisi, 22(1), 3-17.

Rambaut, A., Drummond, A. J., Xie, D., Baele, G., \& Suchard, M. A. (2018). Posterior summarization in Bayesian phylogenetics using Tracer 1.7. Systematic Biology, 67(5), 901-904. https://doi.org/10.1093/sysbio/syy032

Ronquist, F., Teslenko, M., Van Der Mark, P., Ayres, D. L., Darling, A., Höhna, S., Larget, B., Liu, L., Suchard, M. A., \& Huelsenbeck, J. P. (2012). MrBayes 3.2: 
1060

1061

1062

1063

1064

1065

1066

1067

1068

1069

1070

1071

1072

1073

1074

1075

1076

1077

1078

1079

1080

1081

1082

1083

1084

1085

1086

1087

1088

1089

1090

1091

1092

1093

1094

1095

1096

1097

1098

1099

Efficient bayesian phylogenetic inference and model choice across a large model space. Systematic Biology, 61(3), 539-542.

Rueda-Ramírez, D., Santos, J. C., Sourassou, N. F., Demite, P. R., Puerta-González, A., \& De Moraes, G. J. (2019). Complementary description of Africoseius lativentris and placement of Africoseius in Podocinidae (Acari, Mesostigmata) based on molecular and morphological evidences. Systematic and Applied Acarology, 24(12), 23692394.

Santos, V. V. D., \& Tixier, M. S. (2018). Integrative taxonomy approach for analysing evolutionary history of the tribe Euseiini Chant \& McMurtry (Acari: Phytoseiidae). Systematics and Biodiversity, 16(3), 302-319.

Satou, A., Nisimura, T., \& Numata, H. (2000). Reproductive competition between the burying beetle Nicrophorus quadripunctatus without phoretic mites and the blow fly Chrysomya pinguis. Entomological Science, 3(2), 265-268.

Schäffer, S., \& Koblmüller, S. (2020). Unexpected diversity in the host-generalist oribatid mite Paraleius leontonychus (Oribatida, Scheloribatidae) phoretic on Palearctic bark beetles. PeerJ, 8. https://doi.org/10.7717/peerj.9710

Schedwill, P., Geiler, A. M., \& Nehring, V. (2018). Rapid adaptation in phoretic mite development time. Scientific Reports, 8(1),1-10. https://doi.org/10.1038/s41598-01834798-6

Schedwill, P., Paschkewitz, S., Teubner, H., Steinmetz, N., \& Nehring, V. (2020). From the host's point of view: Effects of variation in burying beetle brood care and brood size on the interaction with parasitic mites. PloS one, 15(1), e0228047.

Schwarz, H. H. (1996). Host range and behavioral preferences in german sibling species of the Poecilochirus carabi complex (Acari: Mesostigmata: Parasitidae). International Journal of Acarology, 22(2), 135-140.

Schwarz, H. H., \& Koulianos, S. (1998). When to leave the brood chamber? Routes of dispersal in mites associated with burying beetles. Experimental and Applied Acarology, 22(11), 621-631.

Schwarz, H. H., \& Müller, J. K. (1992). The dispersal behaviour of the phoretic mite Poecilochirus carabi (Mesostigmata, Parasitidae): adaptation to the breeding biology of its carrier Necrophorus vespilloides (Coleoptera, Silphidae). Oecologia, 89(4), 487-493.

Schwarz, H. H., Starrach, M., \& Koulianos, S. (1998). Host specificity and permanence of associations between mesostigmatic mites (Acari: Anactinotrichida) and burying beetles (Coleoptera: Silphidae: Nicrophorus). Journal of Natural History, 32(2), 159-172.

Scott, M. P. (1998). The ecology and behavior of burying beetles. Annual Review of Entomology, 43, 595-618. https://doi.org/10.1146/annurev.ento.43.1.595

Sikes, D. S., Madge, R. B., \& Newton, A. F. (2002). A catalog of Nicrophorinae (Coleoptera: Silphidae) of the world. In Zootaxa 65. 
1100 Sikes, D. S., Trumbo, S. T., \& Peck, S. B. (2016). Cryptic diversity in the New World burying beetle fauna: Nicrophorus hebes Kirby; new status as a resurrected name (Coleoptera: Silphidae: Nicrophorinae). Arthropod Systematics and Phylogeny, 74(3), 299-309.

Sikes, D. S., Vamosi, S. M., Trumbo, S. T., Ricketts, M., \& Venables, C. (2008). Molecular systematics and biogeography of Nicrophorus in part-The investigator species group (Coleoptera: Silphidae) using mixture model MCMC. Molecular Phylogenetics and Evolution, 48(2), 646-666.

Sikes, D. S., \& Venables, C. (2013). Molecular phylogeny of the burying beetles (Coleoptera: Silphidae: Nicrophorinae). Molecular Phylogenetics and Evolution, 69(3), 552-565. by the burying beetle, Nicrophorus pustulatus, a parasitoid of snake eggs. Journal of Evolutionary Biology, 20(6), 2389-2399. sequences for their use in species identification. Frontiers in Zoology, 4(6), 1-12.

Springett, B. P. (1968). Aspects of the relationship between burying beetles, Necrophorus spp. And the mite, Poecilochirus necrophori Vitz. The Journal of Animal Ecology, 417-424.

Stadler, T. (2010). Sampling-through-time in birth-death trees. Journal of Theoretical Biology, 267(3), 396-404. (2018). The fossilized birth-death model for the analysis of stratigraphic range data under different speciation modes. Journal of Theoretical Biology, 447, 41-55.

Stamatakis, A. (2014). RAxML version 8: A tool for phylogenetic analysis and postanalysis of large phylogenies. Bioinformatics, 30(9), 1312-1313.

Stefan, L. M., Gómez-Díaz, E., Mironov, S. V., González-Solís, J., \& McCoy, K. D. (2018). "More than meets the eye": Cryptic diversity and contrasting patterns of host-specificity in feather mites inhabiting seabirds. Frontiers in Ecology and Evolution, 6(JUL), 1-16. determines the value of a mutualism between species. Evolution Letters, 3(2), 185197.

Sun, S.-J., \& Kilner, R. (2019). Cryptic host specialisation within Poecilochirus carabi mites explains population differences in the extent of co-adaptation with their burying beetle Nicrophorus vespilloides hosts. BioRxiv, 1223(3), 641936.

Swafford, L., \& Bond, J. E. (2010). The symbiotic mites of some Appalachian Xystodesmidae (Diplopoda: Polydesmida) and the complete mitochondrial genome sequence of the mite Stylochyrus rarior (Berlese) (Acari: Mesostigmata: Ologamasidae). Invertebrate Systematics, 23(5), 445-451. 
Thompson, J. N. (2009). The coevolving web of life. American Naturalist, 173(2), 125140. https://doi.org/10.1086/595752

Tiffney, B. H. (1985). The Eocene North Atlantic Land Bridge: Its importance in Tertiary and modern phytogeography of the Northern Hemisphere. Journal of the Arnold Arboretrum, 66, 243-274.

Wen, J., Nie, Z. L., \& Ickert-Bond, S. M. (2016). Intercontinental disjunctions between eastern Asia and western North America in vascular plants highlight the biogeographic importance of the Bering land bridge from late Cretaceous to Neogene. Journal of Systematics and Evolution, 54(5), 469-490.

Wettlaufer, J. D., Burke, K. W., Schizkoske, A., Beresford, D. V., \& Martin, P. R. (2018). Ecological divergence of burying beetles into the forest canopy. PeerJ, 2018(11), 1-18.

Wilson, D. S. (1982). Genetic Polymorphism for Carrier Preference in a Phoretic Mite. BioScience, 32(6), 537-537.

Wilson, D. S., \& Knollenberg, W. G. (1987). Adaptive indirect effects: The fitness of burying beetles with and without their phoretic mites. Evolutionary Ecology, 1, 139159.

Wise, G. U., Hennessey, M. K., \& Axtell, B. C. (1988). A New Species of ManureInhabiting Mite in the Genus Poecilochirus (Acari: Mesostigmata: Parasitidae) Predacious on House Fly Eggs and Larvae. Entomological Society of America, 81(2), 209-224.

Witaliński, W. (2000). Aclerogamasus stenocornis sp. n., a fossil mite from the Baltic amber (Acari: Gamasida: Parasitidae). Genus, 11(4), 619-626.

Xin, T., Que, S., Zou, Z., Wang, J., Li, L., \& Xia, B. (2016). Complete Mitochondrial Genome of Euseius nicholsi (Ehara et Lee) (Acari: Phytoseiidae). Mitochondrial DNA Part A, 27(3), 2167-2168.

Yoder, J. B., \& Nuismer, S. L. (2010). When does coevolution promote diversification? American Naturalist, 176(6), 802-817. https://doi.org/10.1086/657048

Young, M. R., Proctor, H. C., deWaard, J. R., \& Hebert, P. D. N. (2019). DNA barcodes expose unexpected diversity in Canadian mites. Molecular Ecology, 28(24), 53475359.

Zhang, G., Basharat, U., Matzke, N., \& Franz, N. M. (2017). Model selection in statistical historical biogeography of Neotropical insects - The Exophthalmus genus complex (Curculionidae: Entiminae). Molecular Phylogenetics and Evolution, 109, 226-239.

Zhisheng, A., Kutzbatch, J. E., Prell, W. L., \& Porder, S. C. (2001). Evolution of Asian monsoons and phased uplift of the Himalaya- Tibetan plate since Late Miocene times. Nature, 411, 62-66. 